ARTICLE

https://doi.org/10.1038/s41467-019-11910-6

\title{
The transcribed pseudogene RPSAP52 enhances the oncofetal HMGA2-IGF2BP2-RAS axis through LIN28B-dependent and independent let-7 inhibition
}

\author{
Cristina Oliveira-Mateos¹, Anaís Sánchez-Castillo1,2, Marta Soler (10 1, Aida Obiols-Guardia1, David Piñeyro (1) 1, \\ Raquel Boque-Sastre (10) 1,3, Maria E. Calleja-Cervantes ${ }^{1}$, Manuel Castro de Moura ${ }^{1}$, Anna Martínez-Cardús (iD ${ }^{1}$, \\ Teresa Rubio4, Joffrey Pelletier (1) 4, Maria Martínez-Iniesta ${ }^{5}$, David Herrero-Martín (1) 6, Oscar M. Tirado (1) 2,6, \\ Antonio Gentilella (iD ${ }^{4,7}$, Alberto Villanueva ${ }^{5}$, Manel Esteller (1) 1,2,8,9,10, Lourdes Farré5,11 \& Sonia Guil (1) 1,10
}

One largely unknown question in cell biology is the discrimination between inconsequential and functional transcriptional events with relevant regulatory functions. Here, we find that the oncofetal HMGA2 gene is aberrantly reexpressed in many tumor types together with its antisense transcribed pseudogene RPSAP52. RPSAP52 is abundantly present in the cytoplasm, where it interacts with the RNA binding protein IGF2BP2/IMP2, facilitating its binding to mRNA targets, promoting their translation by mediating their recruitment on polysomes and enhancing proliferative and self-renewal pathways. Notably, downregulation of RPSAP52 impairs the balance between the oncogene $L I N 28 B$ and the tumor suppressor let-7 family of miRNAs, inhibits cellular proliferation and migration in vitro and slows down tumor growth in vivo. In addition, high levels of RPSAP52 in patient samples associate with a worse prognosis in sarcomas. Overall, we reveal the roles of a transcribed pseudogene that may display properties of an oncofetal master regulator in human cancers.

\footnotetext{
${ }^{1}$ Cancer Epigenetics and Biology Program (PEBC), Bellvitge Biomedical Research Institute (IDIBELL), L'Hospitalet de Llobregat, Barcelona, Catalonia, Spain. ${ }^{2}$ Centro de Investigación Biomédica en Red de Cáncer (CIBERONC), Carlos III Institute of Health (ISCIII), Madrid, Spain. ${ }^{3}$ Cardiff School of Biosciences, Cardiff University, Museum Avenue, Cardiff CF10 3AX Wales, UK. ${ }^{4}$ Laboratory of Cancer Metabolism, ONCOBELL Program, Bellvitge Biomedical Research Institute (IDIBELL), L'Hospitalet de Llobregat, Barcelona, Catalonia, Spain. ${ }^{5}$ Program Against Cancer Therapeutic Resistance (ProCURE), ICO, IDIBELL, L'Hospitalet de Llobregat, Barcelona, Catalonia, Spain. ${ }^{6}$ Sarcoma Research Group, ONCOBELL Program, Bellvitge Biomedical Research Institute (IDIBELL), L'Hospitalet de Llobregat, Barcelona, Catalonia, Spain. ${ }^{7}$ Department of Biochemistry and Physiology, Faculty of Pharmacy, University of Barcelona (UB), Barcelona, Catalonia, Spain. ${ }^{8}$ Physiological Sciences Department, School of Medicine and Health Sciences, University of Barcelona (UB), Barcelona, Catalonia, Spain. ${ }^{9}$ Institució Catalana de Recerca i Estudis Avançats (ICREA), Barcelona, Catalonia, Spain. ${ }^{10}$ Josep Carreras Leukaemia Research Institute (IJC), Badalona, Barcelona, Catalonia, Spain. ${ }^{11}$ Laboratory of Experimental Pathology (LAPEX), Gonçalo Moniz Research Center, Oswaldo Cruz Foundation (CPQGM/FIOCRUZ), Salvador, Bahia, Brazil. Correspondence and requests for materials should be addressed to L.F. (email: mfarre@idibell.cat) or to S.G. (email: sguil@carrerasresearch.org)
} 
$\mathrm{T}$ he largest part of the mammalian genome is transcribed into RNA species with little or no coding potential, known as noncoding RNAs (ncRNAs) ${ }^{1}$. Although their biological roles are still largely unknown, a growing number of long noncoding RNAs (lncRNAs, a label arbitrarily assigned to transcripts longer than 200 nucleotides) display regulatory properties by acting at all levels in gene expression control (from epigenetic modifications and chromatin dynamics to the control of posttranscriptional messenger RNA stability and translation) ${ }^{2,3}$. In some cases, their key functions in normal homeostasis and development links the dysregulation of their expression with causal roles in cancer ${ }^{4}$, and there are instances of lncRNAs involved in each of the cancer hallmarks, including sustained proliferative signaling and growth (e.g., ANRIL ${ }^{5}$, lincRNA-p216, MEG $3^{7}$ ), invasion and metastasis (e.g., HULC, MALAT1 ${ }^{9}$, HOTAIR $^{10}$ ), resistance to cell death (e.g., PCGEM1 ${ }^{11}$ ), and replicative immortality (e.g., TERC ${ }^{12}$, TERRA ${ }^{13}$ ). Mechanisms of action include the interaction with other nucleic acids and/ or protein factors, which confers the ability to function as scaffolds, guides, decoys, or allosteric regulators of several nuclear or cytoplasmic processes ${ }^{14,15}$. In a growing number of examples, their roles intertwine with that of the betterstudied miRNAs ${ }^{16}$, either by cooperating in their function ${ }^{17}$ or by impairment of the miRNA-mediated regulation ${ }^{18}$. The latest annotation in GENCODE estimates that up to 16,000 genes in the human genome correspond to lncRNAs, and a similar number is given to pseudogenes (https://www.gencodegenes.org/stats/ current.html\#). Although some pseudogenes do code for proteins, the majority are thought to be lncRNAs owing to the accumulation of mutations in the definition of the open reading frames, and as such their biological functions include the ability to regulate gene expression similarly to $\operatorname{lncRNAs} s^{19}$, and are thereby also involved in growth-regulatory roles in cancer ${ }^{20}$.

RPSAP52 is a pseudogene-transcribed RNA that runs antisense to the oncofetal gene $H M G A 2$, a transcriptional co-regulator that is expressed at high levels during embryonic development, silenced in virtually all adult tissues and re-expressed in several human cancers, where its levels are generally associated with the presence of metastases and poor prognosis ${ }^{21,22}$. Our previous results indicate that RPSAP52 positively regulates HMGA2 expression through the formation of an $\mathrm{R}$ loop structure ${ }^{23}$. Herein we further study the role of this transcribed pseudogene in breast and sarcoma tumors, and uncover its role as a pro-growth factor through the regulation of the IGF2BP2/IGF1R/RAS axis and the balance between LIN28B and let-7 levels.

\section{Results}

RPSAP52 impacts on IGF2BP2 and let-7 in breast cancer cells. We have previously uncovered the positive impact of the expression of the pseudogene RPSAP52 on its sense, protein-coding gene HMGA2 (Fig. 1a) ${ }^{23}$. Both genes are generally expressed at low levels in differentiated normal tissues and overexpressed in a number of human cancers, including breast cancer, concomitant with a hypomethylation of the associated $\mathrm{CpG}$ island (Fig. 1b). In breast cancer patients, a positive correlation between the expression of both genes is observed (Fig. 1c), as is also seen in the NCI60 panel of cell lines (Supplementary Fig. 1a). Other studies have reported that high HMGA2 expression predicts poor outcome in breast cancer patients ${ }^{25}$. Since our observations indicate that knockdown of RPSAP52 results in a reduction in HMGA2 expression $^{23}$, we decided to look further into the molecular mechanism of RPSAP52-mediated regulation of the locus. A panel of breast cancer cell lines was used to confirm the presence of RPSAP52 transcript by semi-quantitative PCR (Fig. 1d). Surprisingly, most cell lines expressed the annotated RPSAP52 transcript
(Refseq NR_026825.2) together with an additional species that corresponds to the inclusion of a 104-nucleotides-long internal exon (Fig. 1d and Supplementary Fig. 1b). Evidence as to the presence of this alternative exon in the spliced transcript can also be found in the MiTranscriptome database ${ }^{24}$, which catalogs long polyadenylated RNA transcripts (www.mitranscriptome.org, with reference G018828|T081486). The quantitative measurement of expression levels indicates that HMGA2 mRNA and the two isoforms of RPSAP52 are 2-3 orders of magnitude overexpressed when there is hypomethylation of the promoter-associated $\mathrm{CpG}$ island, as shown with Illumina's HumanMethylation450 BeadChip analysis (Fig. 1e) and was confirmed by bisulfite sequencing at the nucleotide level (Supplementary Fig. 1c). Altogether, these observations confirm the coordinate expression of both genes and their silencing in hypermethylated conditions. RPSAP52 is annotated as a noncoding RNA in Refseq, but is labeled as coding in some coding potential calculator tools. Pseudogenes are more likely to give false positive results in programs such as PhyloCSF (since they are similar to their parental protein-coding, and PhyloCSF evaluates conservation to predict coding capacity). We thus conducted in vitro transcription/translation assays, which confirmed the absence of RPSAP52 coding potential (Supplementary Fig. 2a). However, analysis of RNA presence along sucrose gradients from MCF10A cells showed the presence of RPSAP52 transcripts in polysomal fractions, indicating a role in translation. Interestingly, a strong correlation in co-sedimentation of HMGA2 mRNA and RPSAP52 transcript was observed (Supplementary Fig. 2b-e). Indeed, further characterization of RPSAP52 transcripts showed that they are enriched in the cytoplasm (Fig. 1f) and polyadenylated (Fig. 1g), suggesting additional roles besides the ability to regulate HMGA2 transcription in the nucleus. In order to identify protein partners of RPSAP52 that could help characterize its activity, we performed RNA pull-down assays combined with mass spectrometry (MS). In vitro synthesized full-length RPSAP52 RNA was incubated in the presence of MCF10A extracts and the retrieved proteins were analyzed by SDS-PAGE. As shown in Fig. $2 \mathrm{a}$, a protein band of $\sim 70 \mathrm{kDa}$ is specifically pulled-down by RPSAP52 RNA, but not by its antisense sequence or another unrelated RNA. This band was characterized by MS, which identified two proteins within the isolated fragment: the insulin-like growth factor 2 mRNA-binding protein 2 (IGF2BP2), also known as IMP2 (from which seven peptides were identified), and the heterogeneous nuclear ribonucleoprotein Q (HNRNPQ), also known as SYNCRIP (identified with six peptides) (Supplementary Fig. 3a). IGF2BP2, together with IGF2BP1 and IGF2BP3 partakes of a family of RNA binding proteins that have been implicated in post-transcriptional control, including the regulation of mRNA localization, stability, and translation ${ }^{26}$. Similar to HMGA2, although the expression of IGF2BPs is normally restricted to embryonic stages, they are re-expressed upon malignant transformation, playing roles in the maintenance of cancer stem cells and the promotion of tumor growth ${ }^{27}$. Western blot with specific antibodies confirmed that both IGF2BP2 and HNRNPQ are enriched in the RPSAP52 pull-down, and analysis of RPSAP52 truncates indicate that the two isoforms are able to bind to these two factors (Fig. 2b). In accordance with the pull-down results, the previously reported consensus binding site for IGF2BP2, the CAUH $(\mathrm{H}=\mathrm{A}, \mathrm{C}, \mathrm{U})$ motif $^{28}$, is abundant along the two constitutive RPSAP52 exons, but absent on the alternative exon (Supplementary Fig. 3b), suggesting that the alternative splicing event does not impact on the affinity of the binding.

IGF2BP2 is a direct transcriptional target of $\mathrm{HMGA}^{29}$ and both proteins partake of a pro-proliferative axis ${ }^{30,31}$ that interweaves with the function of let-7 family of miRNAs. Both HMGA2 and IGF2BP2 mRNAs are direct targets of let-7, but IGF2BP proteins have been suggested to modulate let-7 action via 
a

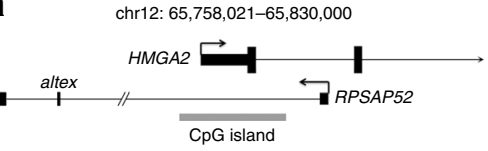

b
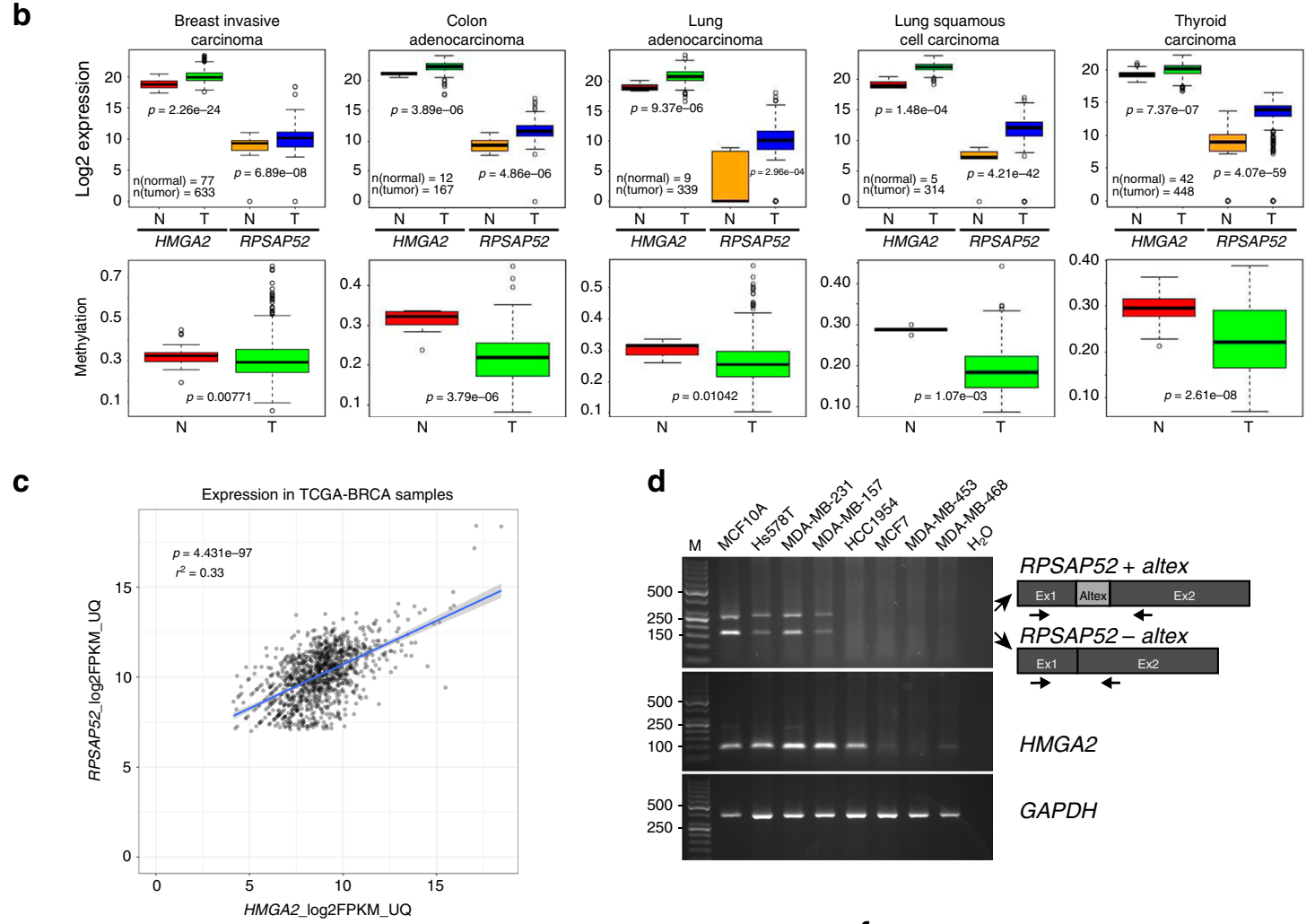

e
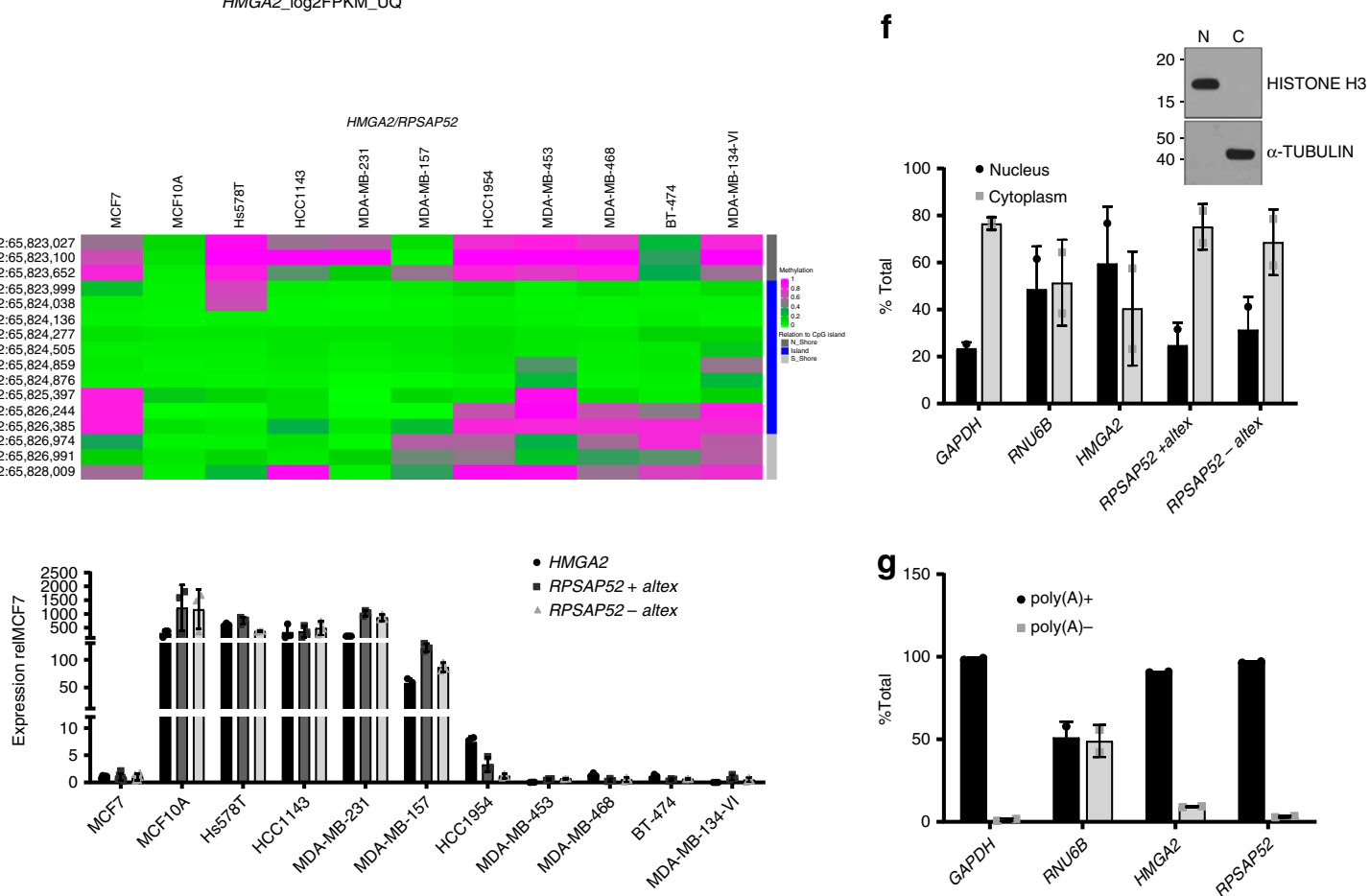

the formation of cytoplasmic mRNPs that would protect certain mRNAs from let-7 binding and repression ${ }^{32,33}$. The most abundantly expressed members of the family are let-7a/b/e in MCF10A cells, and let-7a/d/f/g/i in Hs578T cells (Supplementary Fig. 3c). Interestingly, the levels of the mature form of these
miRNAs were upregulated in RPSAP52-depleted cells, both in MCF10A and Hs578T clones stably expressing shRNAs (Fig. 2c and Supplementary Fig. 3g) and in cells transiently expressing three different locked nucleic acid (LNA)-based antisense oligonucleotides (ASOs) gapmers (Fig. 2e). RPSAP52 has a region 
Fig. 1 Characterization of RPSAP52 expression in breast cancer. a Intronic/exonic organization of sense/antisense transcripts in HMGA2 locus. Coordinates are referred to the UCSC Genome Browser (GRCh38/hg38 release). Only the 5' regions of HMGA2 transcripts are included. b Box plot representations show both HMGA2 and RPSAP52 transcripts are overexpressed in a variety of human cancers compared with normal controls (TCGA dataset) (upper panels), concomitant with hypomethylation of the associated CpG island (lower panels). On each box plot, the central mark indicates the median, and the bottom and top edges indicate the interquartile range (IQR). The box plot whiskers represent either 1.5 times the IQR or the maximum/minimum data point if they are within 1.5 times the IQR. P-values are according to the two-tailed Wilcoxon signed-rank test. c Pearson correlation between HMGA2 and RPSAP52 transcripts in breast cancer primary tumors (all stages included). Normalized values of RNA-seq data from TCGA are represented. d Semiquantitative RT-PCR to detect the expression of HMGA2 and RPSAP52 in a panel of breast cancer cell lines. Detection of RPSAP52 transcripts was done with primers that detect both isoforms. e Upper panel: heatmap representation of the DNA methylation profile for the CpG island-containing promoter at the HMGA2 locus, as analyzed with the 450K DNA methylation microarray. Single CpG methylation levels are shown. Green, unmethylated; magenta,

methylated. Data from 11 breast cancer cell lines are shown. Lower panel: the expression levels of both RPSAP52 (including or excluding the alternative exon) and HMGA2 were analyzed by RT-qPCR and represented relative to MCF7 cell line. Graphs represent the means of three replicates from different RNA extractions \pm SD. $\mathbf{f}$ Nuclear/cytoplasmic fractionation of MCF10A cells, analyzed by RT-qPCR and western blot to assess fraction purity. Graphs represent the mean \pm SD of two replicates of fractionation. $\mathbf{g}$ Poly $(A)+/$ poly $(A)$ - partition of total RNA from MCF10A cells and analysis by RT-qPCR. Primers that detect the RPSAP52 + altex isoform were used. Graphs represent the mean \pm SD of two replicates of poly $(A)$ selection. Source data are provided as a Source Data file

of homology with other RPSA pseudogenes, but none was affected by our depletion strategy (Supplementary Fig. 3d). Also, given the possibility that some pseudogenes regulate parental gene expression, we analyzed the levels of RPSA protein in the RPSAP52depleted cells, but no quantitative change was found (Supplementary Fig. 3e). Of note, gapmer-mediated depletion of $H M G A 2$ increased both RPSAP52 isoforms and resulted in a decrease in let-7 levels, suggesting that the negative regulation exerted by RPSAP52 on the miRNAs is not through HMGA2 pathway (Fig. 2e). Let-7 regulates IGF2BP2 mRNA and other members of IGF1 signaling pathway, among others IGF1R and RAS. Downregulation of RPSAP52 with shRNAs or gapmers reduces the amount of these proteins, in accordance with the increased let-7 levels (Fig. 2d, f and Supplementary Fig. 3g, h). LIN28A and LIN28B are the main negative regulators of let-7 biogenesis, through direct binding to either pre-let-7 and/or pri-let-734,35, but often only one of the two proteins is found expressed in human cancer cell lines ${ }^{36}$. We could not detect LIN28B protein expression in MCF10A cells, and LIN28A was not altered upon RPSAP52 knockdown (Supplementary Fig. 3f), suggesting that changes in let-7 in MCF10A cells were not consequences of impaired biogenesis at the level of regulation by LIN28. However, RPSAP52-mediated regulation of IGF2BP2 protein levels is reverted by overexpression of LIN28B, indicating a convergence on the same regulatory network (Fig. $2 \mathrm{~g}$ ).

Next, the phenotypic impact of the altered control of the IGF2BP2/IGF1R/RAS pathway by RPSAP52 was tested both in vitro and in vivo.

RPSAP52 has oncogenic-like features in vitro and in vivo. Upon RPSAP52 knockdown, all three breast cell lines tested (the nontransformed MCF10A and the tumorigenic Hs578T and HCC1143 cells) proved to be significantly less proliferative in the sulforhodamine B (SRB) assay (Fig. 3a), and had a significantly lower percentage colony formation density than control cells (Fig. 3b). Interestingly, RPSAP52 depletion was also associated with a decreased migration potential (Fig. 3c). High levels of let-7 miRNAs often correlate with a lower capacity for self-renewal and pluripotency. Given the observed reduction in proliferation and migration following RPSAP52 knockdown, we next assessed the levels of markers of cell stemness (Fig. 3d). NANOG and OCT4 protein levels were decreased in RPSAP52-depleted cells, suggesting this lncRNA promotes features of cancer stem cells. This was further confirmed in soft-agar colony formation experiments, in which the measure of the anchorage-independent growth of the cells showed a significant decrease upon depletion of RPSAP52 (Fig. 3e). For the in vivo approach, we next used tumor formation assays in nude mice. MCF10A and Hs578T cells stably expressing either scrambled shRNAs or shRNAs against RPSAP52 were subcutaneously injected into mice, and the tumor formation and volume was monitored. Tumors originating from RPSAP52 knockdown cells had a significantly lower volume and weight at end point than control tumors, both for the non-tumorigenic and the tumorigenic cells (Fig. 3f, g). Importantly, the amount of RAS and IGF2BP2 proteins were markedly reduced in the excised tumors at end point, indicating that the in vitro findings were maintained in the in vivo context (Fig. 3f, g).

RPSAP52 regulates IGF2BP2/LIN28B/let-7 axis in sarcoma. We next attempted to determine whether RPSAP52-mediated regulation of proliferative pathways occurred in other cancer types. The analysis of the collection of human cancers available from The Cancer Genome Atlas (TCGA) indicates HMGA2 and RPSAP52 expression is specially increased in adrenocortical carcinoma, mesothelioma and in the sarcoma samples available (as measured by Z-score, Supplementary Fig. 4a). TCGA RNA expression and DNA methylation data showed that RPSAP52 promoter hypermethylation was associated with transcript downregulation across sarcoma samples (Fig. 4a, upper panel; Pearson correlation, $r^{2}=0.264, P$-value $\left.=4.764 \mathrm{e}-10\right)$. Of note, HMGA2 expression in the same samples shows a poorer correlation (Supplementary Fig. $4 \mathrm{~b}, r^{2}=0.131, P$-value $\left.=2.582 \mathrm{e}-05\right)$. Both genes maintain a positive expression correlation (Fig. $4 \mathrm{a}$, lower panel) and a difference of $\sim 1-2$ orders of magnitude in their relative expression (Supplementary Fig. 4c). This is in agreement with absolute quantification of RPSAP52 and HMGA2 transcripts in MCF10A and A673 cell lines, in which HMGA2 mRNA is 1-2 orders of magnitude at higher levels (Supplementary Fig. 4d). Since the HMGA2-IGF2BP2-RAS pathway has been previously involved in the pathogenesis of embryonic rhabdomyosarcoma ${ }^{31}$, we then assessed HMGA2 and RPSAP52 expression in a panel of cell lines derived from rhabdomyosarcoma and also Ewing's sarcoma (Fig. 4b). Both RPSAP52 isoforms were abundantly expressed in most rhabdomyosarcoma cell lines, with just one order of magnitude higher HMGA2 expression in Rh28, Rh41, or CW9019 cells. In Ewing's sarcoma, RPSAP52 was generally lowly expressed with the exception of A673 cell line. We thus focused on A673 cells to further characterize the molecular function of this IncRNA. As seen in MCF10A cells, RNA pulldowns confirmed the ability of RPSAP52 to interact with IGF2BP2 and SYNCRIP/HNRNPQ (Fig. 4c). Importantly, stable clones expressing two different shRNAs against both RPSAP52 isoforms resulted in a strong increase in let-7 family members (Fig. 4d, upper panel), even when HMGA2 levels were only 
a

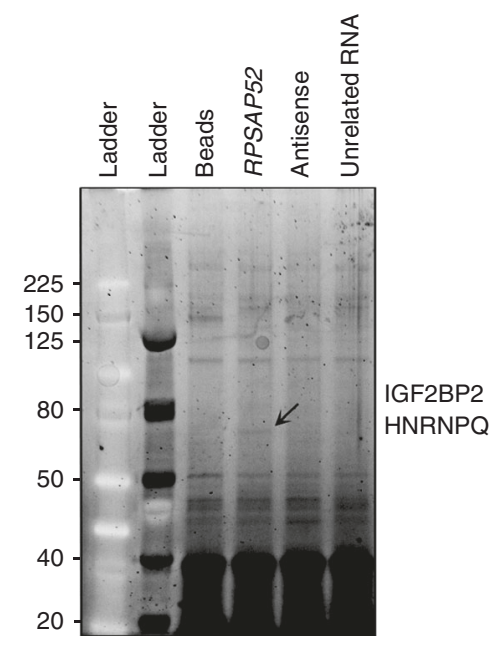

C

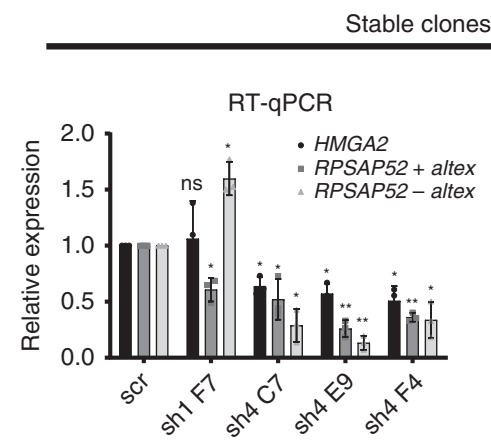

b

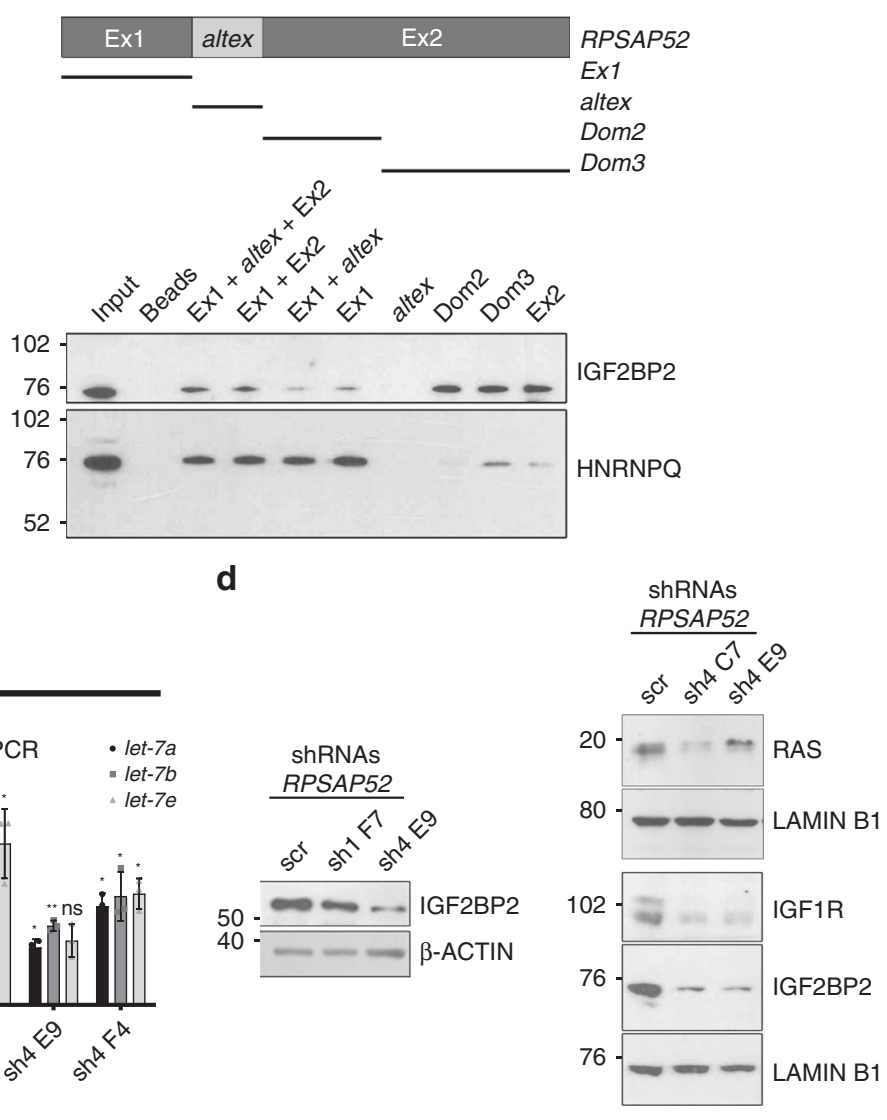

f

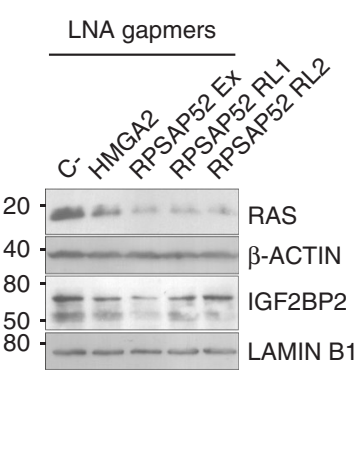

g

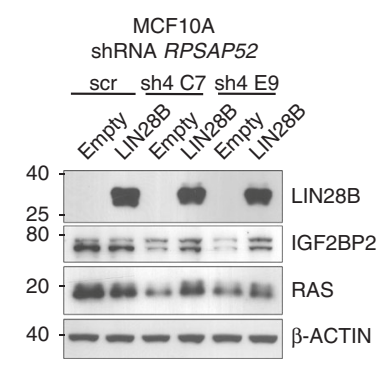

Fig. 2 RPSAP52 interacts with IGF2BP2 and HNRNPQ and influences proliferative pathways in MCF10A cells. a RNA pull-down assay to detect RPSAP52associated proteins. In vitro synthesized full-length RPSAP52 transcript (including the alternative exon) or control sequences (the antisense transcript and the unrelated Uc.160+ RNA) were tested. The proteins retrieved were analyzed by SDS-PAGE and the band of $\sim 70 \mathrm{kDa}$ indicated by the arrow was identified by MS as containing IGF2BP2 and HNRNPQ. b Western blot showing the association between RPSAP52 RNA and IGF2BP2 and HNRNPQ proteins. Different truncated fragments of RPSAP52 RNA (as shown in the upper diagram) were incubated in the presence of MCF10A total protein extracts and the pulled-down material was subject to western blot with specific antibodies. Total extract from the MCF10A cell lines was used as input control, and a reaction without RNA (beads) as negative control. c Stable knockdown of RPSAP52 results in upregulation of let-7 family of miRNAs. Total RNA from MCF10A clones constitutively expressing two different shRNAs against RPSAP52 (sh1 or sh4) was analyzed by RT-qPCR to assess HMGA2 mRNA, RPSAP52 transcripts and let-7 miRNAs levels. Graphs represent the mean \pm SD of three independent RNA extractions. Two-tailed student $t$-test were used $\left({ }^{\star} P<0.05,{ }^{\star \star} P<0.01, \mathrm{~ns}=\right.$ not significant). d Western blot to analyze IGF2BP2, IGF1R, and RAS protein levels upon stable knockdown of RPSAP52 transcripts. e Transient transfection of MCF10A cells with locked nucleic acid (LNA)-based antisense oligonucleotides (ASOs) gapmers targeting HMGA2 mRNA (HMGA2), exon1 (RPSAP52 Ex) or the first intron (RPSAP52 RL1 and RL2) of RPSAP52 transcript. Expression levels of HMGA2, RPSAP52 and let-7 were measured by RT-qPCR. Graphs represent the mean \pm SD of seven independent replicates (for HMGA2 and RPSAP52) or three replicates (for let-7). Two-tailed student $t$-test were used $\left({ }^{\star} P<0.05,{ }^{\star} P P<0.01,{ }^{\star \star \star} P<0.001\right)$. $\mathbf{f}$ Western blot to analyze IGF2BP2 and RAS protein levels upon transient knockdown of RPSAP52 transcripts. $\mathbf{g}$ Western blot to analyze IGF2BP2 and RAS protein levels upon transient overexpression of LIN28B protein in the background of RPSAP52 depletion. Source data are provided as a Source Data file 
a
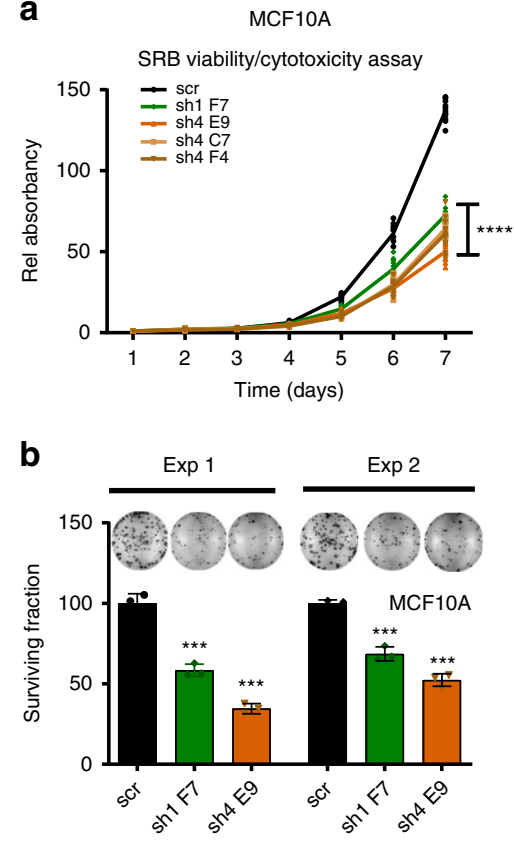

C

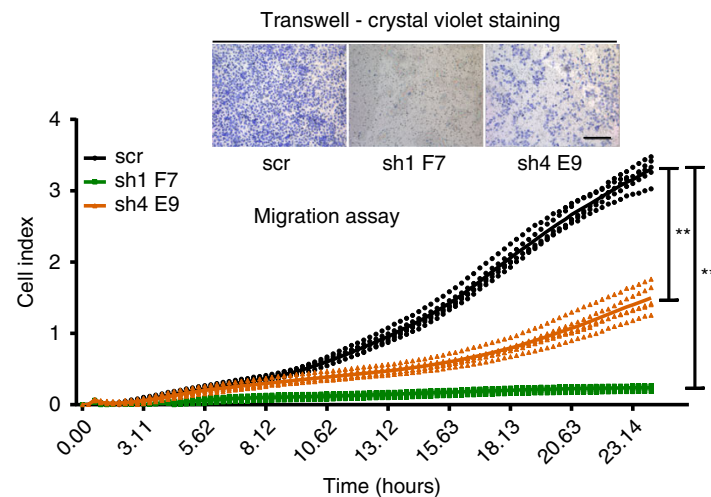

f
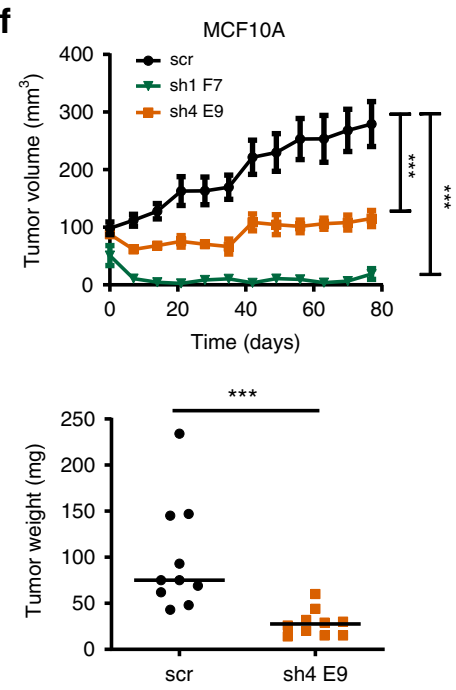

Hs578T
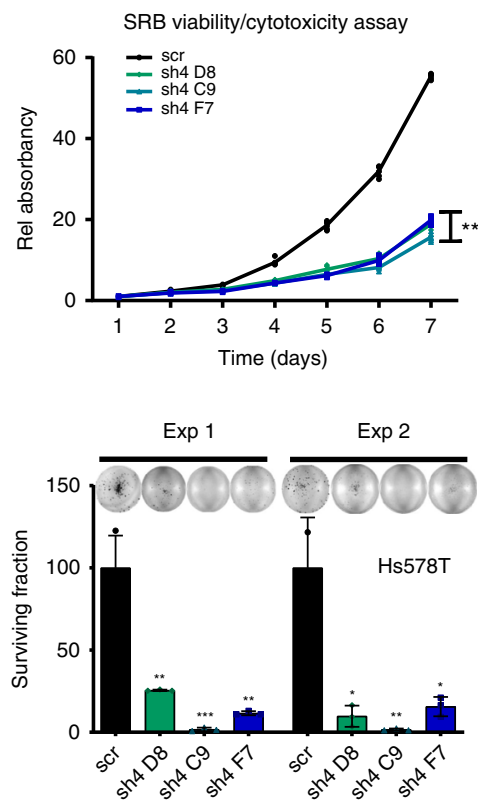

d

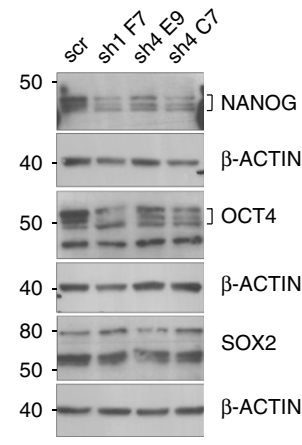

HCC1143

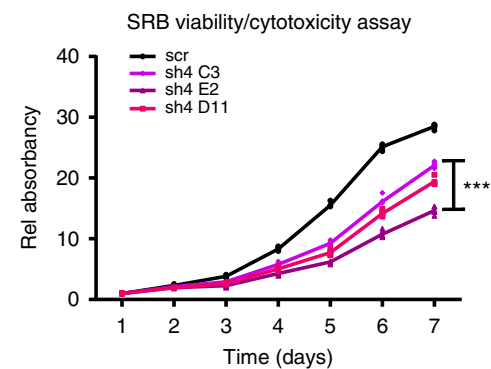

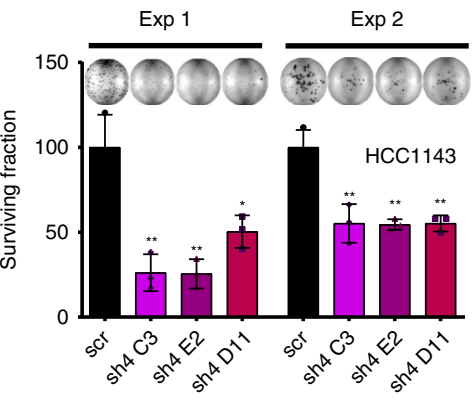

e

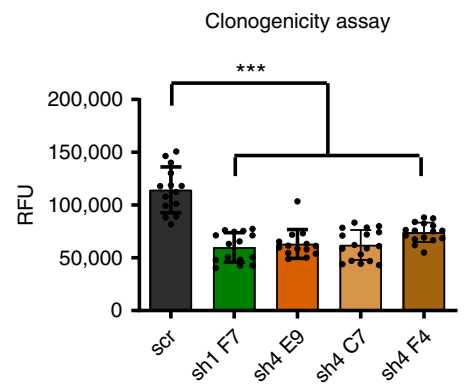

g
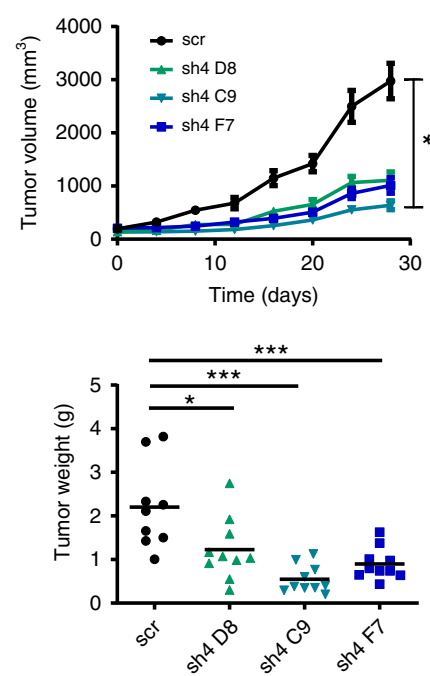

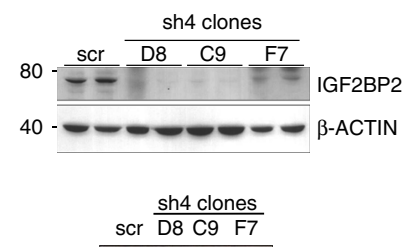

moderately reduced (Fig. $4 \mathrm{~d}$, lower panel). In this case, RPSAP52 knockdown did not correlate with IGF2BP2 decrease, but with a marked reduction in LIN28B protein levels, which in contrast to breast cell lines, is abundantly expressed in A673 cells (Fig. 4e and Supplementary Fig. 4e). Also, while RAS levels were only partially reduced, downstream signaling was impaired, as observed by the decrease in p-ERK levels (Fig. 4e). In an in vivo setting, and similarly to the observations in breast cell lines, this results in a marked reduction in tumor formation when mice are subcutaneously injected with RPSAP52-depleted A673 cells (Fig. 4f). 
Fig. 3 RPSAP52 displays oncogenic features in breast cancer cells. a Viability/cytotoxicity assays in MCF10A, Hs578T and HCC1143 clones. The experiment was performed three times and one representative graph is shown for each cell line. Values are mean \pm SD of $n \geq 6$ measurements. One-way ANOVA was used $\left({ }^{\star \star \star} P<0.001,{ }^{\star \star \star *} P<0.0001\right)$. b Effect of RPSAP52 silencing on colony formation ability. Representative plates are shown. Colonies were counted from three replicate plates and two independent experiments. Values are mean \pm SD. Two-tailed unpaired $t$-test were used $\left({ }^{\star} P<0.05,{ }^{\star \star} P<0.01,{ }^{\star \star \star} P<\right.$ 0.001, $\left.{ }^{\star \star \star \star} P<0.0001\right)$. c Migration capacity of RPSAP52-depleted clones was monitored over $24 \mathrm{~h}$ ( $n=5$ replicates per condition), with higher cell index indicating higher migration. Values are mean \pm SD. A two-tailed Mann-Whitney $U$ test of data at end point was used ( $\left.{ }^{\star \star} P<0.01\right)$. Inset: migration was also assessed with transwells. Scale bar $=100 \mu \mathrm{m}$. d Western blot analysis of NANOG, OCT4, and SOX2 in RPSAP52-depleted cells. e The clonogenic ability was assessed with at least $n=12$ replicates per condition. Values are mean \pm SD. A two-tailed Mann-Whitney $U$ test was used ( $\left.{ }^{\star \star \star} P<0.001\right)$. $\mathbf{f}$ Growthinhibitory effect of RPSAP52 knockdown in MCF10A mice xenografts. Upper graph: tumor volume $(n=10)$ was monitored over time. Mean values are shown \pm SEM. Lower graph: tumors were excised and weighed at 77 days ( ${ }^{\star \star \star} P<0.001$, two-tailed Mann-Whitney $U$ test). Western blot was carried out from sh4 tumors since no material could be recovered from sh1 tumors, and the levels of RAS and IGF2BP2 proteins were analyzed. The photograph shows the relative size of all tumors extracted. Scale bar $=10 \mathrm{~mm}$. g Growth-inhibitory effect of RPSAP52 knockdown in Hs578T mice xenografts. Upper graph: tumor volume ( $n=9$ for scr and $n=10$ for sh4 clones) was monitored over time. Mean values are shown \pm SEM. Lower graph: tumors were excised and weighed at 28 days $\left({ }^{\star} P<0.05,{ }^{* \star} P<0.001\right.$, two-tailed Mann-Whitney $U$ test). Western blot was carried out from tumors at end point and the levels of IGF2BP2 protein were analyzed. The photograph shows the relative size of all tumors extracted. Scale bar $=10 \mathrm{~mm}$. Source data are provided as a Source Data file

Interestingly, LIN28B protein reduction is only partially explained by a decrease in LIN28B mRNA levels (Supplementary Fig. 4f). This discrepancy, together with the interaction detected between RPSAP52 and IGF2BP2, and the presence of RPSAP52 along sucrose gradient's heavy fractions, which correspond to translating poly-ribosomes (see text above and Supplementary Fig. 2d), prompted us to investigate the possibility that LIN28B levels were regulated by the lncRNA at the translational level.

RPSAP52 modulates IGF2BP2 binding to its mRNA targets. IGF2BP2 is a mRNA stability and translational regulator with some well-described targets, such as IGF2 ${ }^{37}$, NRAS ${ }^{31}$, or $\mathrm{HMGA}^{38}$. The closely related IGF2BP1 protein has been shown to interact with LIN28B mRNA and increase LIN28B protein levels in ES-2 cells ${ }^{32}$. In order to assay the interaction of IGF2BP2 with LIN28B mRNA in A673 cells, we carried out protein immunoprecipitation followed by RT-qPCR of the pulled-down RNA. We could confirm the interaction of IGF2BP2 with both RPSAP52 isoforms, with IGF2BP2 and NRAS mRNA, and importantly, with $L I N 28 B$ mRNA. Of note, even though the RPSAP52 isoform lacking the alternative exon is more abundant in A673 cells, both transcripts were recovered in comparable amounts in IGF2BP2 immunoprecipitate, with a $\sim 10$-fold higher affinity of IGF2BP2 for RPSAP52 + altex RNA (Fig. 5a, see RT-qPCR). Further, LIN28B protein was not co-immunoprecipitated with IGF2BP2 protein (Fig. 5b), suggesting its putative regulation by IGF2BP2 is at the level of transcript. We next wanted to test the possibility that this binding is regulated by RPSAP52 presence. Interestingly, whereas binding to IGF1R and IGF2BP2 mRNAs was not altered, binding of IGF2BP2 to LIN28B mRNA was reduced upon stable knockdown of RPSAP52 (Fig. 5c). This suggests that this lncRNA might regulate $L I N 28 B$ post-transcriptionally through modulation of IGF2BP2 function. In view of this, we decided to characterize in a transcriptome-wide manner the IGF2BP2-RNA interactions with individual nucleotide resolution (iCLIP-seq) under control or RPSAP52-knockdown conditions. We identified 290,060 and 131,729 iCLIP-tags in control and RPSAP52-depleted A673 cells, corresponding to 3075 and 1639 peak regions, respectively (Supplementary Fig. 5a, b). As has been shown before, IGF2BP2 iCLIP tags were enriched in $3^{\prime} \mathrm{UTRs}^{28,33}$, with $\sim 60 \%$ of the iCLIP peaks falling within $3^{\prime}$ UTRs in control cells. Remarkably, knockdown of RPSAP52 resulted in a specific decrease in the number of $3^{\prime} \mathrm{UTR}$ peaks revealed by iCLIP and an increase in intronic regions (Fig. 5d). Motif enrichment analysis around the crosslinking-induced truncation sites (CITS) indicate that the previously described $\mathrm{CAUH}(\mathrm{H}=\mathrm{A}, \mathrm{C}, \mathrm{U})$ consensus binding site ${ }^{28}$ also ranks high in our iCLIP experiments, but is more enriched in the control samples (Supplementary Fig. 5c, d). We found 1775 and 810 peaks with the CAUH motif in the control and depleted sample, respectively, representing a statistically significant difference in occurrence (Fisher's exact test $P$-value $=5.286 \mathrm{e}-08)$. In addition, the number of peaks with more than one CAUH motif was higher in the control cells (average number of motifs was 1.81 for control and 1.64 for depleted cells; Mann-Whitney $U$ test, $P$-value $=$ 1.786e-05). The full list of statistically significant iCLIP-seq peaks and CITS can be found in Supplementary Data 1. Differences in motif binding and the reduction in $3^{\prime} \mathrm{UTR}$ recognition results in a shortlist of 34 transcripts with differential IGF2BP2 iCLIP counts along their 3'UTR (Fig. 5e). GO enrichment analysis shows these genes belong to categories that may relate to IGF2BP2 involvement in cancer invasion and metastasis, including cell-substrate adhesion, spreading, and wound healing, as well as the canonical function for IGF2BP2 pathway, cellular glucose homeostasis (Fig. 5e). Of note, previous CLIP experiments for IGF2BPs in pluripotent stem cells have revealed that cell adhesion is also the most significant GO category for CLIP-enriched 3'UTRs for IGF2BP $1^{39}$. This suggests that the levels of RPSAP52 have a dramatic impact on IGF2BP2 global role. In addition, top ten GO categories for genes with significant iCLIP peaks present on their $3^{\prime}$ UTRs in the control sample correspond to signaling pathways and cell cycle progression, whereas none of these categories are enriched in the RPSAP52-depleted sample (Fig. 5f).

Previous CLIP-seq studies with IGF2BP2 had revealed binding sites on the $3^{\prime}$ UTR of LIN28B mRNA in HEK293T cells ${ }^{28}$, and we detected similar sites in our experimental setting and a tendency to decrease upon RPSAP52 depletion, although without any statistical power (Fig. 5g). For other validated IGF2BP2 targets, such as $H M G A 2$, we also detected abundant iCLIP signal corresponding to direct binding of IGF2BP2 to its $3^{\prime} \mathrm{UTR}$. In this case, binding is dramatically lost upon RPSAP52 knockdown (Fig. 5h), and a corresponding decrease in HMGA2 protein level is observed (Supplementary Fig. 5e). This is not a general phenomenon for all IGF2BP2 targets, since other well-characterized mRNA partners, such as HMGA1, NRAS, and IGF1R maintain comparable iCLIP signals in both control and RPSAP52-depleted conditions (Supplementary Fig. 5f). Our results thus suggest a specific loss of IGF2BP2 affinity for particular mRNA targets. Several of the best characterized IGF2BP2 targets are regulated by let-7 (e.g., RAS, HMGA2...) but, interestingly, we could not find a differential presence of let-7 miRNA recognition motifs along the $3^{\prime}$ UTRs of the immunoprecipitated mRNAs in control or depleted samples (Fisher's exact test $P$-value $=0.8974)$. Also, 
a
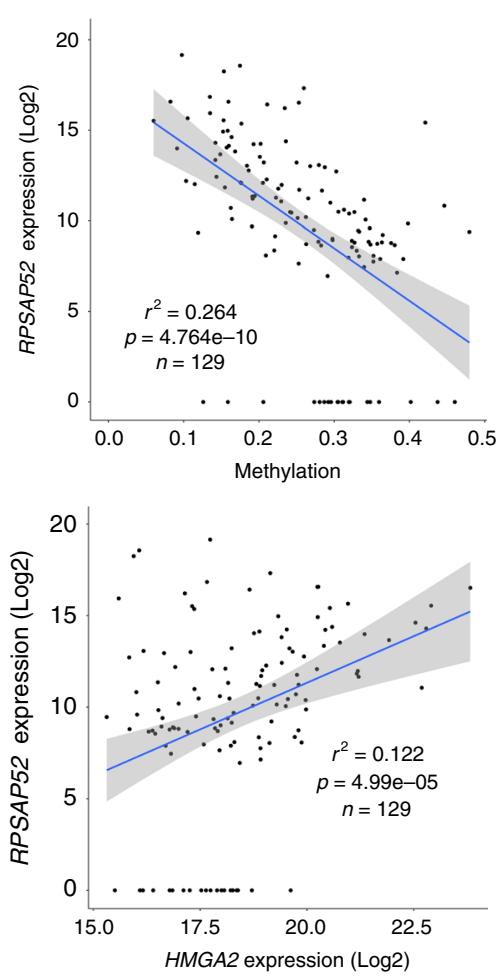

C

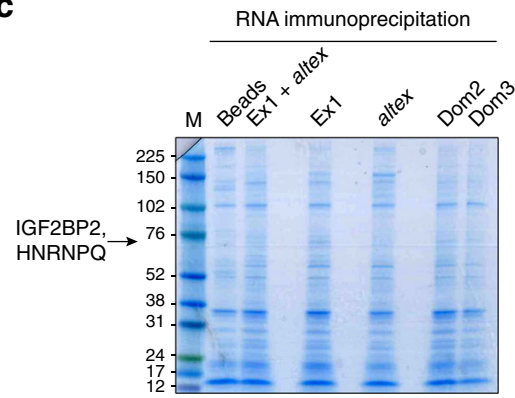

d

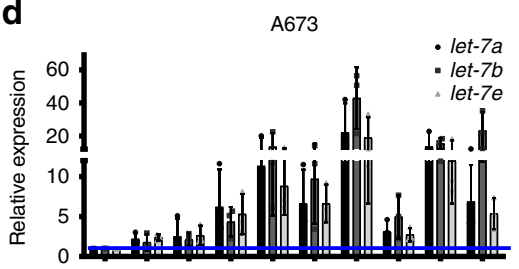
scr D6 E4 F7 G8 B9 B11 C9 D9 E8

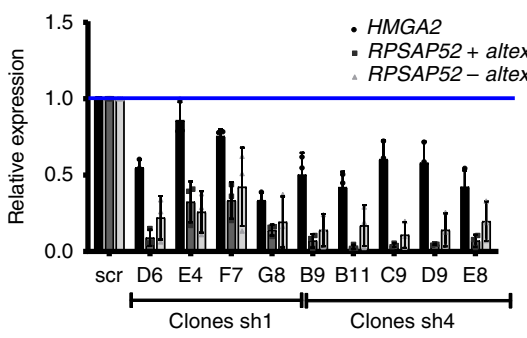

b
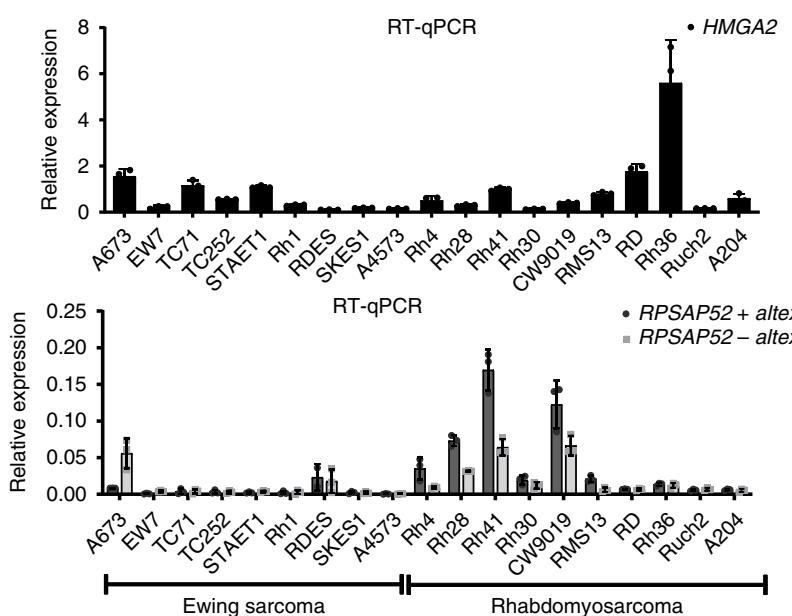

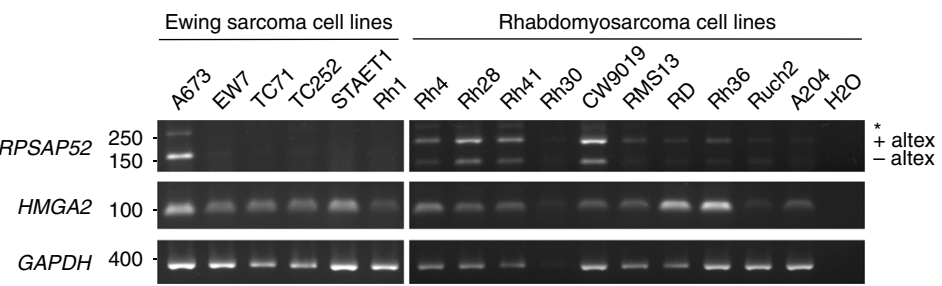

Western blotting
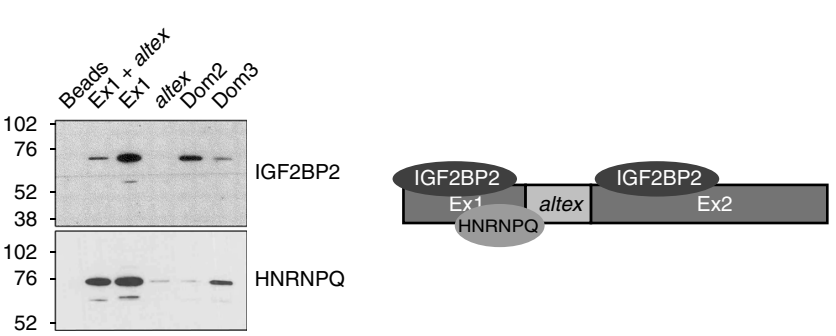

e

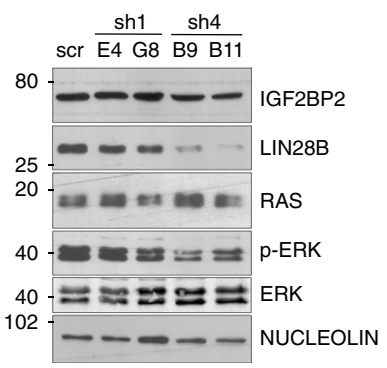

f
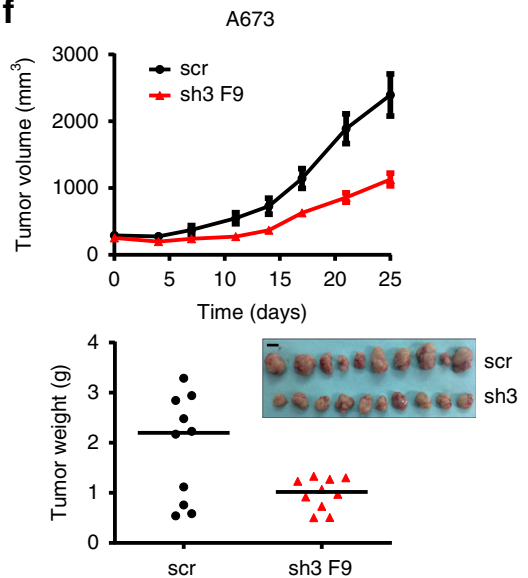

depletion of LIN28B does not impact on IGF2BP2 levels or its binding to mRNA targets, indicating that the regulation of RPSAP52 on IGF2BP2 does not proceed through LIN28B (Supplementary Fig. 5h-j). Both HMGA2 and LIN28B mRNAs are present at high levels upon RPSAP52 depletion (Fig. $4 \mathrm{~d}$ and Supplementary Fig. 4f), and their half-lives are not substantially altered (Supplementary Fig. 5g), pointing to a decrease in their translation as a consequence of a diminished binding to IGF2BP2.

RPSAP52 controls IGF2BP2 and mRNA distribution on polysomes. To obtain direct evidence of the changes in translation efficiency for specific IGF2BP2 targets, we analyzed the 
Fig. 4 RPSAP52 is abundantly expressed in sarcoma and regulates the LIN28B/let-7 balance. a Upper graph: Pearson coefficient between RPSAP52 expression levels and CGI methylation in the TCGA sarcoma cohort indicates a negative correlation. Lower graph: Pearson's index indicates a weaker association between RPSAP52 and HMGA2 expression levels in the same cohort. $\mathbf{b}$ Upper graphs: RT-qPCR analysis to estimate HMGA2 and RPSAP52 expression levels in a panel of Ewing's sarcoma and rhabdomyosarcoma cell lines. Expression is relative to GUSB mRNA levels. Graphs represent the mean \pm SD of three independent RNA extractions. Lower panel: semi-quantitative RT-PCR analysis of expression in the same cell lines. The two RPSAP52 isoforms are indicated, and the highermigrating band depicted by an asterisk contains an additional exonic sequence (encompassing coordinates chr12:66,169,917-66,170,002 (hy19)), detected in those cells lines with the highest expression of RPSAP52. c RNA pull-down assays confirm the interaction of RPSAP52 with IGF2BP2 and HNRNPQ in A673 cell extracts. Different truncated fragments of RPSAP52 were assayed as indicated, and the band identified by MS and corresponding to IGF2BP2 and HNRNPQ is indicated on the protein gel (left). Western blot to test the association between RPSAP52 RNA and IGF2BP2 and HNRNPQ proteins (middle panel). The drawing summarizes the data obtained from the pull-downs (right). d Total RNA from A673 stable clones constitutively expressing sh1 or sh4 shRNA sequences was analyzed by RT-qPCR to assess HMGA2 and RPSAP52 transcripts levels (lower graph) or let-7 miRNAs levels (upper graph). Graphs represent the mean \pm SD of three independent replicates. e Western blot on A673 clones to analyze protein levels upon stable knockdown of RPSAP52 transcripts. f Growth-inhibitory effect of RPSAP52 knockdown in A673 mice tumor xenografts. Upper graph: tumor volume $(n=10)$ was monitored over time. Mean values are shown \pm SEM. Lower graph: tumors were excised and weighed at 25 days. The photograph shows the relative size of all tumors extracted. Scale bar $=10 \mathrm{~mm}$. Source data are provided as a Source Data file

distribution of mRNAs across sucrose gradients in control or RPSAP52-depleted A673 cells. We observed no major changes in the polysome profiles of cells depleted of RPSAP52 when compared with control cells, indicating that RPSAP52 knockdown does not alter the global translational output of the cell (see gradient profiles in Fig. 6a-d and Supplementary Fig. 6a). Surprisingly, we detected a remarkable decrease in the amount of HMGA2 and LIN28B mRNAs associated with polysomes (Fig. 6a, b), indicating a selective regulation in their translation as a function of RPSAP52 expression. This was not observed for NRAS and GAPDH mRNAs (Fig. 6c, d). Analysis of total HMGA2, $L I N 28 B$, and NRAS mRNAs under the same conditions does not justify the specific redistribution of HMGA2 and LIN28B across the gradients (Fig. 6e). These results indicate that the loss of binding to IGF2BP2 previously observed in iCLIP experiments correlates with lower translational efficiency for individual mRNAs, and we next asked whether IGF2BP2 protein itself is redistributed across the gradient. Importantly, even though IGF2BP2 coimmunoprecipitates with the same protein partners in pull-down experiments (Supplementary Fig. 6b, c), its cosedimentation with translating poly-ribosomes is markedly reduced upon RPSAP52 knockdown (Fig. 6f), demonstrating that RPSAP52 expression mediates the recruitment of IGF2BP2 on polysomes. Taken together, the results suggest that the absence of the pseudogene decreases the recruitment of IGF2BP2 to large polysomes, thereby impacting on the translation of specific mRNAs.

RPSAP52 alters key pathways and is a biomarker in sarcoma. The influence of RPSAP52 on IGF2BP2 binding affinity to its multiple mRNA targets might reflect the impact of this pseudogene on the control of several cellular processes. To identify such processes we interrogated general gene expression with an expression microarray platform under conditions of RPSAP52 knockdown by shRNAs. As shown in Fig. 7a, 1\% of the $\sim 30,000$ interrogated Entrez Gene RNAs were downregulated following knockdown, and $0.7 \%$ of the transcripts were upregulated. In agreement with a regulation mainly at the level of translation, none of the genes with differential IGF2BP2 binding along the $3^{\prime} \mathrm{UTR}$, as seen by iCLIPseq, is deregulated in the expression array analysis, indicating that (i) the differential binding observed is not a consequence of altered transcript expression, and (ii) none of the IGF2BP2 targets whose interaction with this protein is influenced by RPSAP52 see their stability significantly altered as a consequence. However, they might participate in similar cellular pathways, since GO terms analysis indicated that the subset of downregulated genes was enriched in components of response to stimulus and signaling, whereas upregulated genes appeared more involved in development (Fig. 7a). The full list of altered transcripts (fold change $>2$, unpaired $t$-test $P$-value $<0.05)$ can be found in Supplementary Data 2. Among the downregulated genes, molecular functions that were overrepresented included genes involved in receptor binding and growth factor activity (e.g., TIAM1, STYK1, $A R E G, M I C B)$ and sulfur compound binding (CYR61 and MGST1). Of note, MGST1 is involved in the glutathione metabolism pathway and a marker of Ewing's sarcoma prognosis ${ }^{40}$, high levels of NPY (a direct target of the EWS-FLI1 fusion) promotes the metastasis of Ewing's sarcoma models in vivo ${ }^{41}$, CRABP1 and CPT1C favor tumor malignancy ${ }^{42,43}$, and CD109 and PTPRZ1 are highly expressed in several cancer types (including sarcoma cell lines ${ }^{44}$ ) and promote stem cell-like properties ${ }^{45}$. Among the upregulated genes, genes involved in cytoskeletal protein binding were enriched and included MTSS1, a regulator of actin dynamics whose loss increases metastatic potential in a number of cancer types $^{46,47}$ (Supplementary Fig. 7a). The results from the expression arrays were validated by RT-qPCR under conditions of depletion of RPSAP52 where HMGA2 levels are largely unaffected (probably because the R-loop forming, nuclear RPSAP52 is not effectively depleted by shRNAs), and with two different shRNAs that target distant regions on RPSAP52 transcripts (Fig. 7b and Supplementary Fig. 7b). These results indicate that RPSAP52 depletion implies a decrease in proliferative and self-renewal programs and suggests its potential as a biomarker in human samples. In support of this, patients with high RPSAP52 expression levels had poorer prognosis than cases with low expression in the sarcoma patients cohort from TCGA database, whereas HMGA2 expression did not show any prognostic effect in the same cohort (Fig. 7c). Since RPSAP52 expression negatively correlates with hypermethylation of the associated CpG island (Fig. 4a), methylation itself is also a marker of better prognosis (Fig. 7d), reinforcing the relevance of considering lncRNA expression regulation in translational medicine.

Taken together, our results suggest that the pseudogene RPSAP52 controls the HMGA2/IGF2BP2/LIN28B axis through a double mechanism that involves, in the nucleus, the positive transcriptional regulation of $H M G A 2$, and in the cytoplasm, the regulation of the function of IGF2BP2 protein as a translational co-regulator (among others, of LIN28B and HMGA2 mRNAs), which in turn results in a downregulation of let-7 miRNAs and derepression of their pro-proliferative targets (see diagram depicting our working model in Fig. 7e). RPSAP52 thus displays characteristics of an oncogenic gene whose dysregulation might contribute to the progression of a number of human cancers.

\section{Discussion}

The detailed mechanism by which lncRNAs may contribute to altering the output of signal transduction pathways is largely 
a
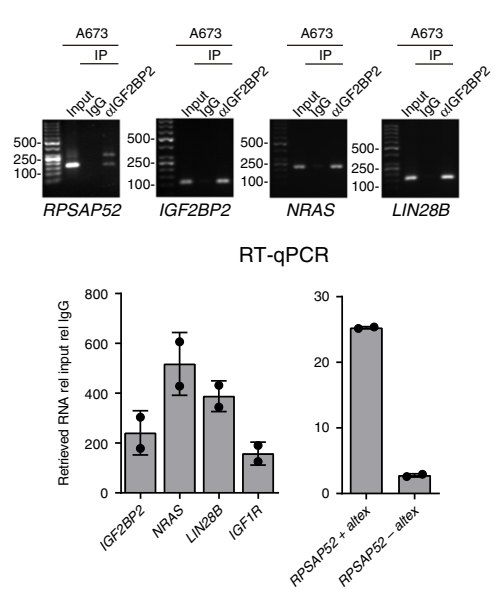

d

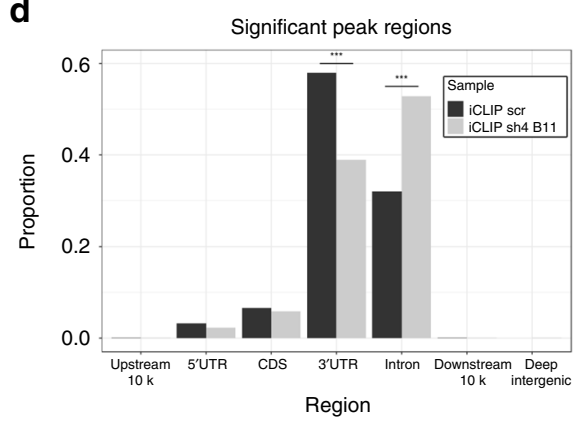

$\mathbf{f}$

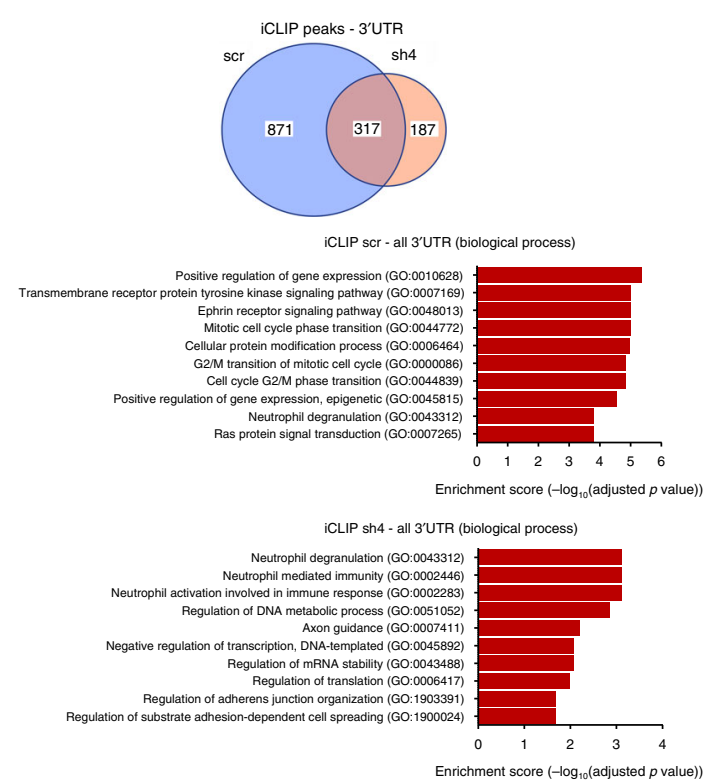

e b

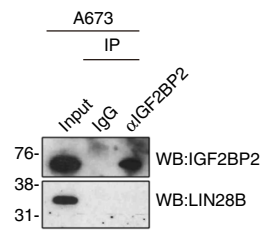

C

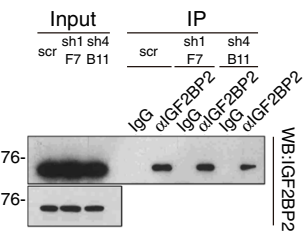

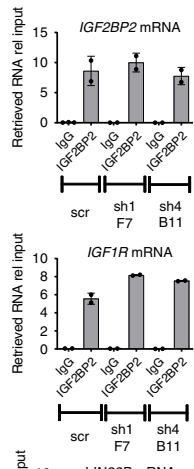

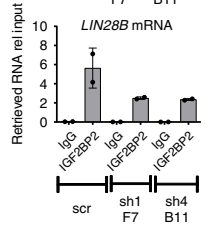

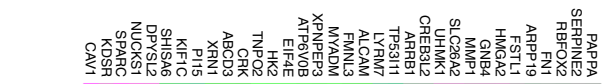

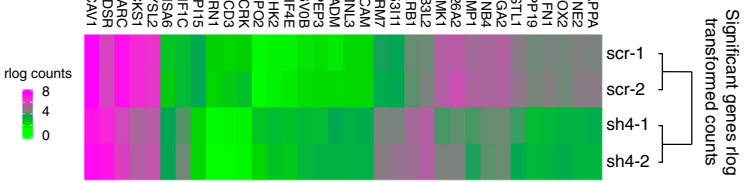

ICLIP - differentially bound 3'UTRs (biological process)

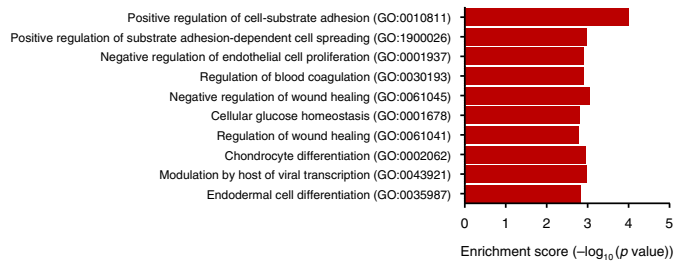

g

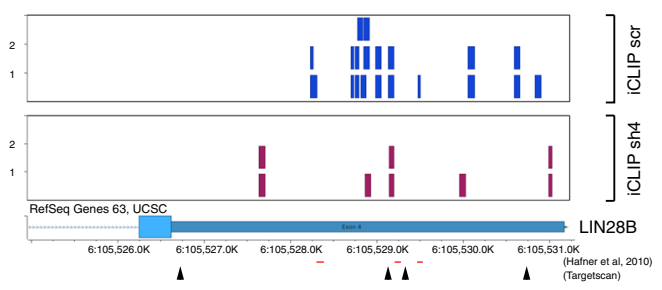

h

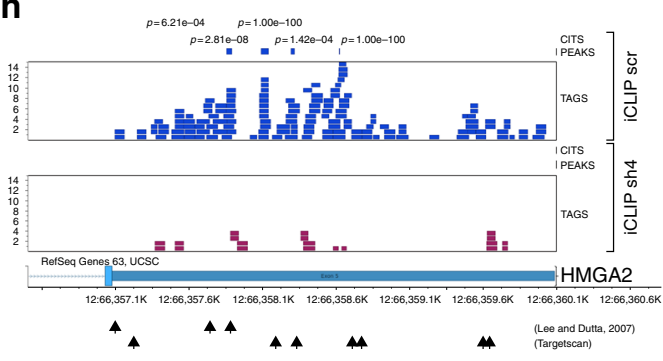

unexplored. Our previous work had shown that the transcribed pseudogene RPSAP52 enhances HMGA2 transcription through the formation of an $\mathrm{R}$ loop structure ${ }^{23}$. We have further explored the impact of RPSAP52 expression in cell physiology and propose a mechanism of action that also influences post-transcriptional regulation in the cytoplasm through the interaction with the RNA binding protein IGF2BP2. Regulation of IGF2BP2 expression or function by lncRNAs appears as a common theme in a number of lineage commitment programs, including adipocyte, cardiac or muscle differentiation ${ }^{48-50}$. However, while other studies have reported lncRNAs that interact with IGF2BP2 and compete for its binding to target mRNAs (e.g., LncMyoD promotes muscle differentiation by outcompeting $c-M y c$ and $N$-Ras mRNAs for IGF2BP2 binding ${ }^{48}$ ), in the cancer setting that we are studying 
Fig. 5 Binding of IGF2BP2 to its mRNA targets is affected by RPSAP52 knockdown. a IGF2BP2 was immunoprecipitated from A673 extracts and the pulleddown RNA was analyzed by RT-PCR. The IGF2BP2 and NRAS mRNAs were used as positive controls. Gel images represent semi-quantitative RT-PCR, whereas data on graphs represent means of two independent RT-qPCR analysis \pm SD. $\mathbf{b}$ Immunoprecipitation of IGF2BP2 from A673 extracts followed by western blot of retrieved proteins. 10\% of total extract prior to IP was loaded as control (input). c IGF2BP2 was immunoprecipitated in control or RPSAP52depleted A673 cells, and the retrieved proteins and RNAs were isolated and analyzed by western blot (left) or RT-qPCR (right), respectively. Graphs correspond to means from two replicates \pm SD. d Analysis of IGF2BP2 binding targets from iCLIP-seq experiments in control (scr) or depleted cells (sh4 B11). The absolute number of peaks mapping to 3'UTR regions were 1762 (scr) and 622 (sh4), and to intronic regions were 973 (scr) and 846 (sh4). Asterisks correspond to $P$-values < 2.2e-16 (two-tailed Fisher's tests). e Above: heatmap of genes with differential iCLIP counts on their 3 'UTR. Results from two experiments are shown. Below: differential enrichment of these genes according to GO biological process categories (top ten are shown). f Above: Venn diagram showing the relation between genes with significant iCLIP peaks present on their 3'UTR regions in the control (scr) or RPSAP52depleted (sh4) sample. Below: top ten GO enrichment categories (Biological process) for the same genes in the scr or sh4 sample. $\mathbf{g}$ UCSC Genome Browser view of LIN28B 3'UTR with the read coverage from IGF2BP2 iCLIP experiment. Previous IGF2BP2-CLIP data positions are shown in red, and predicted let-7 binding sites are indicated by the arrows. h UCSC Genome Browser view of HMGA2 3'UTR with the read coverage from IGF2BP2 iCLIP experiment. Position of significant peaks and CITS are shown above the profiles, and predicted let-7 binding sites are indicated by the arrows. Source data are provided as a Source Data file

reexpression of RPSAP52 facilitates IGF2BP2 binding to a subset of mRNA targets, prominently HMGA2 and LIN28B mRNAs. Our data indicate that this is achieved through modulation of the binding affinity that IGF2BP2 has for particular 3'UTRs and its distribution in large polysomes. This is reminiscent of the mechanism of action of HIF1A-AS2 in glioblastoma cell lines, where binding of an antisense transcript to IGF2BP2 and DHX9 stimulates expression of their target mRNAs and promotes adaption to hypoxic stress ${ }^{51}$. Thus, our working model is that by forming ternary complexes (IGF2BP2-RPSAP52-other mRNAs), RPSAP52 may influence the recruitment into ribonucleoprotein particles that dictate mRNA fate, and in particular enhance the translation of mRNAs that would otherwise be repressed by miRNAs. Binding by IGF2BP3 (another member of the IGF2BP family), for instance, has been associated with resistance to miRNA-dependent destabilization for many oncogenes, including $H M G A 2$ and $L I N 28 B^{52}$. We hereby describe a similar scenario for IGF2BP2, and IGF2BPs are thus emerging as key nodes that integrate lncRNA-mediated post-transcriptional regulation of gene expression and pro-proliferative and self-renewal axis.

An important added layer of regulation exerted by RPSAP52 is the influence on let-7 levels, which may be a consequence of the control on LIN28B translation efficiency, or (in those cells where LIN28B is absent, such as MCF10A), may derive from the altered levels observed in IGF2BP2 protein itself upon depletion of the pseudogene. In fact, in glioblastoma cells lacking LIN28, let-7 targets have been observed to be protected from miRNAdependent silencing by the binding of IGF2BP2 to let-7 miRNA responsive elements ${ }^{27}$. This in turn may indirectly cause a decrease of let-7 levels, since miRNA turnover might also depend on binding to mRNA targets, with some previous evidence suggesting that target availability prevents miRNA decay ${ }^{53,54}$. The greater effect of directly inhibiting biogenesis versus indirectly influencing the turnover might explain why let-7 levels increase moderately in MCF10A upon RPSAP52 depletion (where LIN28B is not expressed and LIN28A is not altered, but IGF2BP2 levels decrease), and, by contrast, increase by almost one order of magnitude more in A673 cells (where expression of LIN28B protein is reduced) (compare Figs. $2 \mathrm{c}$ and $4 \mathrm{~d}$ ). Taken as a whole, RPSAP52 is a pseudogene with an important impact on a major tumor suppressor miRNA. While silencing of HMGA2 expression by let-7 has been reported before ${ }^{55}$, this is the first time that regulation of let-7 levels by transcripts originating from HMGA2 locus is proposed. Importantly, this effect does not proceed through HMGA2 itself, since depletion of HMGA2 expression with gapmers actually increases RPSAP52 levels and consequently results in a decrease in let-7 family (Fig. 2e). This adds further complexity to the regulatory network, one hypothesis being that the tumorigenic cell activates an alternative pathway (increase of RPSAP52) to compensate for the loss of HMGA2 function.

Consistent with their convergent roles in the same pathway, low expression of HMGA2/RPSAP52 in differentiated cells and reexpression in cancer mirrors LIN28 levels, which is one of the key players in maintenance of the pluripotent state. Let-7 levels are maintained low in embryonic stem cells and certain primary tumors due to inhibition by LIN28 proteins, which are present at characteristically high levels in undifferentiated cells ${ }^{56,57}$. Of all tumor suppressor miRNAs, let-7 is the one whose loss is most frequently correlated with poor prognosis in meta-analysis reports ${ }^{58}$. Accordingly, LIN28A/B high expression is a marker of poor prognosis and more aggressive tumors in a variety of cancers, and their levels have also been associated with metastatic and drug-resistant cases ${ }^{59}$. Thus, regulation of LIN28B/let-7 balance is one important driver in cancer development.

An important aspect of this LIN28B/let-7 balance is their counteracting action on the stemness characteristics of cancer cells. Interestingly, LIN28B/let-7 signaling has been shown to regulate endogenous Oct 4 and Sox 2 expression by using ARID3B and HMGA2 as downstream effectors, and thereby regulate stemness properties in oral squamous cancer ${ }^{60}$. Also, the role of let-7 in antagonizing self-renewal and promoting differentiation has been established via targeting of Myc, Ras, and HMGA2 pathways ${ }^{61,62}$. In accordance with let-7 anti-pluripotency properties, we observe a decrease in NANOG and OCT4 levels as well as in clonogenicity upon RPSAP52 depletion (Fig. 3d, e), suggesting that RPSAP52 is an enhancer of stem cell characteristics. To date, few lncRNAs have been thoroughly described regarding their involvement in stemness, among them H19 (whose downregulation reduces NANOG, OCT4, and SOX2 in glioma and breast cancer ${ }^{63}$ ) and lncRNA ROR (which inhibits proliferation of glioma stem cells by negatively regulating KLF4 ${ }^{64}$ ). In particular, H19 has recently been proposed to facilitate tumorigenesis through sponging of let-765. The regulatory mechanism used by RPSAP52, by contrast, targets let-7 family through modulation of LIN28B and/or target availability.

Taken together, we have observed that RPSAP52 (1) stimulates proliferative and self-renewal axes together with a reduction of let-7 levels, (2) promotes tumorigenic behavior in vitro and in vivo, and (3) is overexpressed in a number of human cancers and its expression is associated with worse outcome. This, together with its virtual absence in normal differentiated cells and embryonic expression pattern allows us to propose that RPSAP52 is an oncofetal pseudogene that enhances proliferative 

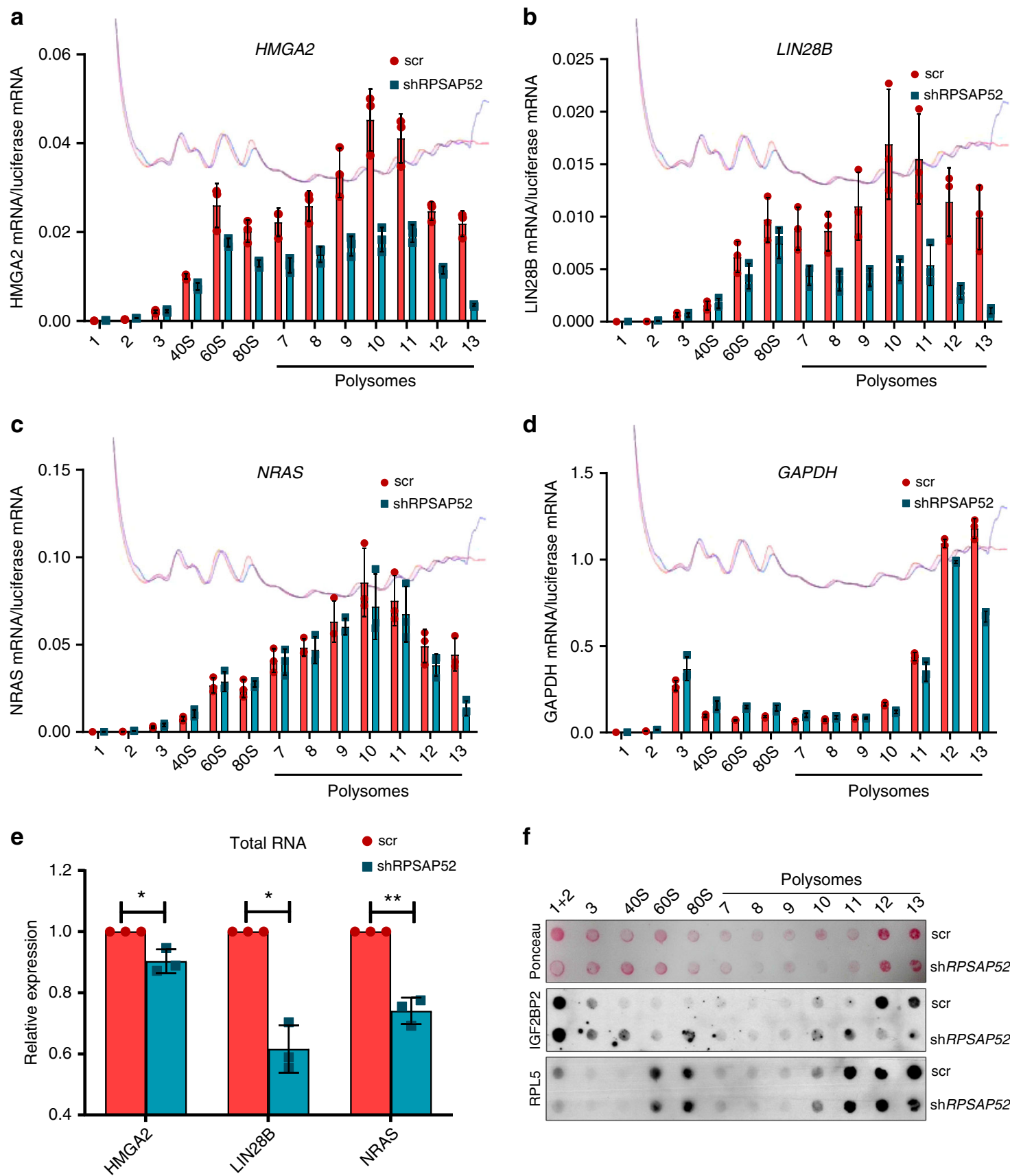

$\mathbf{f}$

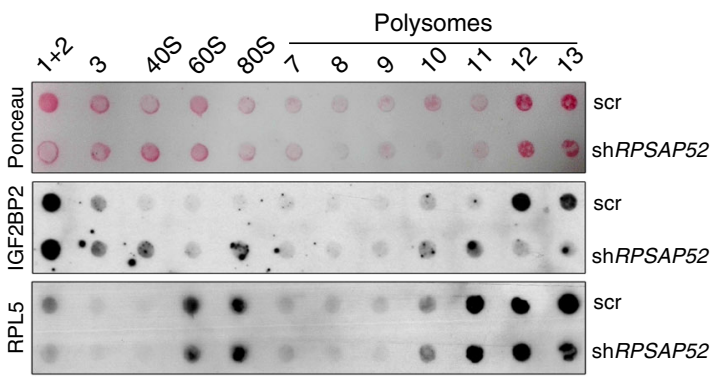

Fig. 6 IGF2BP2 is redistributed on polysome gradients upon RPSAP52 depletion. a-d Polysome profiles of A673 cells stably depleted of RPSAP52 (shRPSAP52, corresponding to sh4 B11 clone) or control cells (scr). HMGA2 mRNA (a), LIN28B mRNA (b), or NRAS mRNA (c) distribution across the gradient was evaluated in each fraction by RT-qPCR. For comparison, GAPDH mRNA distribution was also assessed (d). Graphs represent the mean \pm SD of three replicates. The red and blue lines indicate absorbance at $260 \mathrm{~nm}$ for each fraction in control or depleted cells, respectively. e Total RNA from the same cells $(n=3)$ was analyzed by RT-qPCR. Mean values are shown \pm SD. A two-tailed student $t$-test was used $\left({ }^{\star} P<0.05,{ }^{\star \star} P<0.01\right)$. $\mathbf{f}$ Protein extracted from the $20 \%$ of the polysome profile fractions shown in (a-d) were subjected to dot blot analysis with an anti-IGF2BP2 antibody (middle panel) or with anti-RPL5 antibody as control (lower panel). Proteins from $10 \%$ of fractions 1 and 2 were loaded together. Membranes were previously stained with Ponceau S (top panel) for loading control. Source data are provided as a Source Data file

and survival programs across several tumor types and whose expression in cancer can have important clinical implications. Indeed, RPSAP52 levels are more useful as biomarkers in sarcoma than HMGA2 mRNA levels, which do not seem to correlate well with protein levels (as suggested by our work and others ${ }^{66}$ ), probably due to the complex post-transcriptional regulation of HMGA2. The potential use of this pseudogene as an effective therapeutic target in human cancer will thus be the focus of future studies.

\section{Methods}

DNA methylation analysis. Genome-wide DNA methylation analysis was performed with the 450K DNA methylation microarray from Illumina (Infinium HumanMethylation450 BeadChip). Bisulfite-treated DNA from the indicated breast cancer cell lines was hybridized onto the array. A three-step normalization procedure was performed using the lumi package v2.30.0 (available for Bioconductor, within the R v3.4.3 statistical environment), consisting of color bias and background level adjustment and quantile normalization across arrays. The methylation level ( $\beta$-value) of $\mathrm{CpG}$ sites was calculated as the ratio of methylated signal divided by the sum of methylated and unmethylated signals. 

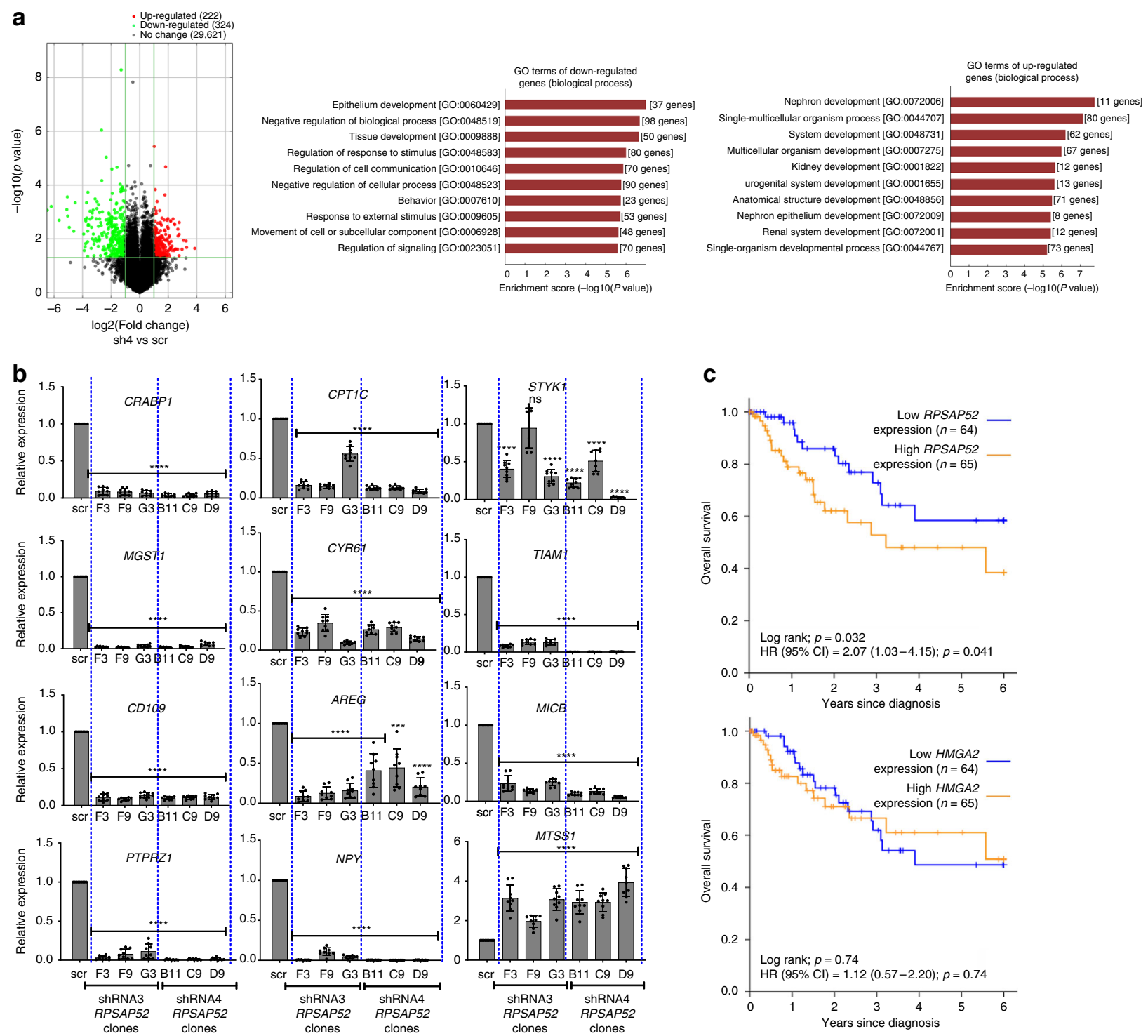

$\mathbf{C}$
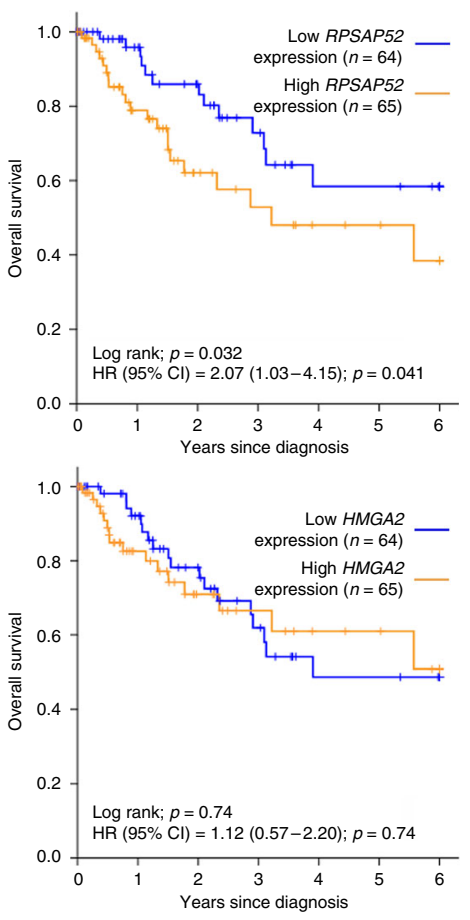

d

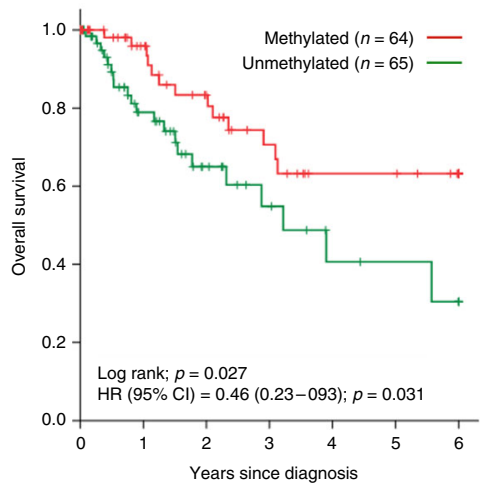

Bisulfite genomic sequencing. The Methyl Primer Express v1.0 software (Applied Biosystems) was used to design specific primers for the methylation analysis of HMGA2/RPSAP52 island (Supplementary Table 1). Genomic DNA $(1 \mu \mathrm{g})$ was subjected to sodium bisulfite treatment using the EZ DNA Methylation-Gold kit (Zymo Research). For bisulfite genomic sequencing, 300-500 bp fragments were amplified using 1-2 $\mu \mathrm{l}$ of bisulfite-converted DNA with Immolase Taq polymerase (Bioline) for 42 cycles. The resulting PCR products were gel-purified with NucleoSpin ${ }^{\circledR}$ Gel and PCR Clean-up (Macherey-Nagel) and then cloned into the pSpark ${ }^{\circledR}$ TA vector (Canvas) according to the manufacturer's protocol. For all samples, 10 colonies were e

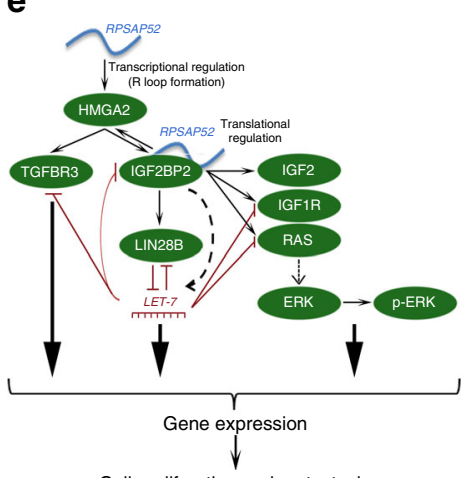

Cell proliferation and metastasis

randomly chosen, the DNA was purified using NucleoSpin ${ }^{\circledR} 96$ Plasmid (Macherey-Nagel) and sequenced by the 3730 DNA Analyzer (Applied Biosystems). After sequencing analysis with BioEdit v7.2.5 software, C nucleotides that remained unaltered were transformed into percentages of CpGs showing methylation.

Western blotting. Cell pellets were resuspended in lysis buffer $(50 \mathrm{mM}$ Tris- $\mathrm{HCl} \mathrm{pH}$ $8,5 \mathrm{mM}$ EDTA, $350 \mathrm{mM} \mathrm{NaCl}, 0.5 \% \mathrm{NP} 40,10 \%$ glycerol, $0.1 \%$ SDS and phosphatase inhibitors), sonicated and centrifuged to recover the supernatant. The concentration 
Fig. 7 RPSAP52 expression influences proliferative cellular programs and is a prognosis factor. a Left: Volcano plot indicating differential expression (green = down, red = up) between control (scr) and RPSAP52-depleted (sh4) A673 cells. The vertical green lines correspond to 2.0-fold up and down, respectively, and the horizontal green line represents a $P$-value of 0.05 (two-tailed unpaired $t$-test). Right: enriched GO terms for shRNA-RPSAP52-affected genes. The $y$ axis shows GO terms and the $x$ axis shows statistical significance (two-tailed Fisher's exact test). $\mathbf{b}$ RT-qPCR analysis of candidate genes altered in RPSAP52-depleted A673 cells. Clones stably expressing two different shRNAs were analyzed. Graphs represent the mean \pm SD of three replicates (two-tailed unpaired student $t$-test, ${ }^{\star \star \star} P<0.001,{ }^{\star \star \star \star \star} P<0.0001$ ). c Above: in the TCGA sarcoma cohort, Kaplan-Meier analysis of overall survival indicates that patients with high RPSAP52 expression levels have poorer prognosis than cases with low expression. Below: HMGA2 expression has no prognostic value in the same cohort. Significance of the log-rank test is shown. d Kaplan-Meier analysis of overall survival in the sarcoma cohort from TCGA, indicating that patients with a hypermethylated HMGA2/RPSAP52 promoter display better prognosis. e Summary of the results in the context of HMGA2/ IGF2BP2/let-7 axis. RPSAP52 positively regulates HMGA2 expression through both transcriptional and post-transcriptional mechanisms. Binding of RPSAP52 to IGF2BP2 in the cytoplasm might promote downregulation of let-7 levels by LIN28B-dependent and independent mechanisms. This binding could also modulate the formation of mRNPs for a number of IGF2BP2 mRNA targets, thereby directing their translation efficiency. Source data are provided as a Source Data file

was determined with the Pierce BCA Protein Assay Kit (\#23227, ThermoFisher). Proteins were boiled for $5 \mathrm{~min}$ with Laemmli buffer (2\% SDS, 10\% glycerol, $60 \mathrm{mM}$ Tris-Cl pH 6.8, $0.01 \%$ bromophenol blue) plus $2 \% 2$-mercaptoethanol as a loading buffer, and equal amounts of extracts were loaded onto Tris-Glycine-SDS gels. Proteins were transferred to a nitrocellulose membrane (Whatman, GE Healthcare) and incubated overnight at $4{ }^{\circ} \mathrm{C}$ with primary antibodies diluted in $5 \%$ skimmed milk in PBS containing 0.1\% Tween-20. The detected proteins were IGF2BP2 (H00010644M01, Abnova, 1:500), RAS (ab55391, Abcam, 1:500, which recognizes all RAS proteins), LIN28B (ab71415, Abcam, 1:1000), IGF1R (\#3027, Cell Signaling, 1:1000), ERK (\#4695, Cell Signaling, 1:1000), p-ERK (\#9101, Cell Signaling, 1:1000), LAMIN B1 (ab16048, Abcam, 1:4000), LIN28A (\#8641, Cell Signaling, 1:750), $\alpha$-TUBULIN HRP (ab40742, Abcam, 1:5000), HNRNPQ (ab184946, Abcam, 1:10,000), $\beta$-ACTIN HRP (a3854, Sigma, 1:20,000), NANOG (\#4903, Cell Signaling, 1:2000), OCT4 (\#2750, Cell Signaling, 1:1000), SOX2 (\#4195, Cell Signaling, 1:1000), NUCLEOLIN (\#8031, Santa Cruz, 1:2000), HMGA2 (ab97276, Abcam, 1:1000), HISTONE H3 (ab1791, Abcam, 1:5000), RPSA (ab133645, Abcam, 1:1000), and RPL5 (A303-933A, Company Bethyl, 1:1000). After three washes with PBS containing $0.1 \%$ Tween-20, membranes were incubated for $1 \mathrm{~h}$ at room temperature in a bench-top shaker with the secondary antibodies conjugated to horseradish peroxidase anti-rabbit IgG (A0545, Sigma, 1:10,000) or anti-mouse IgG (NA9310, GE HealthCare, 1:5000). ECL reagents (Luminata-HRP; Merck-Milllipore) were used to visualize the proteins.

\section{Nuclear/cytoplasmic fractionation and poly(A) selection. Subcellular fractio-} nation was performed with PARIS ${ }^{\text {mi }}$ kit (\#AM1921, Life Technologies). Equal amounts of RNA from each fraction were subject to RT-qPCR and the results were normalized taking into account the total quantity of RNA recovered from each fraction. To verify the nuclear and cytoplasmic fractionation of the mRNA, RNU6B and GAPDH were used as controls, respectively. The separation was confirmed at the protein level by western blot with HISTONE H3 (ab1791, Abcam, 1:5000) and a-TUBULIN HRP (ab40742, Abcam, 1:5000). Poly(A) + and poly(A)- RNAs were separated using the Dynabeads ${ }^{\circledR}$ mRNA Purification kit (\#61006, Life Technologies), using three rounds of selection. RNA enrichment in each fraction was then analyzed by RT-qPCR, using GAPDH and RNU6B as controls.

RNA-biotin pull-down. Full-length RPSAP52 (including alternative exon) or truncated fragments, as well as the antisense version or the sequence corresponding to the unrelated Uc. $160+$ RNA, were biotin-labeled by standard in vitro transcription reactions and gel-purified. DNA templates for transcription were prepared by PCR with oligos described in Supplementary Table 1. The pull-downs were carried out with $10 \mathrm{pmol}$ of each biotinylated RNA and $1 \mathrm{mg}$ of total MCF10A or A673 protein extracts. Following incubation with the extract, each RNA was retrieved with $25 \mu$ lof Dynabeads ${ }^{\circledR}$ M-270 Streptavidin beads (\#65305, Invitrogen) and washed in RIP buffer $(150 \mathrm{mM} \mathrm{KCl}, 25 \mathrm{mM}$ Hepes at pH 7.9, $5 \mathrm{mM}$ EDTA, $0.5 \mathrm{mM}$ DTT, $0.5 \% \mathrm{NP} 40,1 \times$ protease inhibitor cocktail (Roche)). Binding proteins were released through boiling in SDS loading buffer and samples were run on a $4-12 \%$ gradient pre-cast Bis-Tris protein gels (Invitrogen) in MOPS buffer. After electrophoresis, the gels were either stained with SYPRO Ruby (Invitrogen) for band visualization and MS analysis or transferred to nitrocellulose membranes for western blotting.

In-gel digestion and LC-MS/MS analysis. Gel bands were manually excised and digested with trypsin overnight. Bands were then washed with water, $50 \mathrm{mM}$ ammonium bicarbonate and $50 \%$ acetonitrile. Samples were subsequently reduced with $10 \mathrm{mM}$ DTT and alkylated with $35 \mathrm{mM}$ iodoacetamide. Extracted peptides were analyzed on a Ion Trap Amazon Speed ETD (Bruker Daltonics, Bremen, Germany) fitted with a captivespray source (Bruker, Daltonisc) following separation with Easy-nLCII apparatus (Proxeon). Peptides were separated in a reverse phase chromatography using a nano-capillary analytical c18 column. Peptide masses were analyzed at full scan MS, and then at MS/MS fragmentation for the most intense peaks. Data were analyzed using the Mascot search engine and the SwissProt human database.

Reverse pull-down. Endogenous IGF2BP2 was immunoprecipitated from A673 cell extracts. One milligram of total protein was incubated overnight with $2 \mu \mathrm{g}$ of anti-IGF2BP2 polyclonal antibody (\#H00010644-M01, Abnova) or control mouse IgG antibody (\#12-371, Millipore) and $40 \mu \mathrm{l}$ of Dynabeads ${ }^{\circledR} \mathrm{M}-280$ anti-mouse IgG beads (\#11202D, ThermoFisher) in $1 \mathrm{ml}$ of RIP buffer ( $150 \mathrm{mM} \mathrm{KCl}, 25 \mathrm{mM}$ Hepes at $\mathrm{pH} 7.9,5 \mathrm{mM}$ EDTA, $0.5 \mathrm{mM}$ DTT, $0.5 \%$ NP40, $1 \times$ protease inhibitor cocktail (Roche)). Beads were then washed three times with RIP buffer and $10 \%$ of the volume was boiled in the presence of Laemmli buffer for western blot analysis. The pulled-down RNA in the remaining $90 \%$ of beads was extracted by adding $1 \mathrm{ml}$ of TRIzol $^{\circledR}$ Reagent (15596-018, ThermoFisher). After phenol extraction and isopropanol precipitation, the final pellet was resuspended in $10 \mu \mathrm{l}$ of $\mathrm{H}_{2} \mathrm{O}$ and retrotranscribed. cDNA was analyzed by either 30 cycles of semi-quantitative RT-PCR or by RT-qPCR (Applied Biosystems 7900HT Fast Real-Time PCR System). Two micrograms of input RNA was processed in parallel to estimate pull-down efficiency.

Cell culture. MCF7, MCF10A, HCC1143, and A673 cell lines were purchased from ATCC. The remaining breast and sarcoma cell lines were obtained from Dr. Esteller and Dr. Tirado's labs, respectively. Authenticity of the cell lines was routinely confirmed by STR profiling analysis done at qGenomics SL (Esplugues de Llobregat, Barcelona, Spain). All cell lines were routinely checked for mycoplasma contamination. Non-malignant MCF10A breast cells were grown in DMEM/Ham's F-12 medium (\#L0093-500, Biowest) supplemented with $20 \mathrm{ng} \mathrm{ml}^{-1}$ EGF (\#SRP3027, Sigma), $500 \mathrm{ng} \mathrm{ml}^{-1}$ hydrocortisone (\#H0888, Sigma), and $10 \mu \mathrm{g} \mathrm{ml}^{-1}$ insulin (\#I9278, Sigma). Ewing's sarcoma A673 cells and breast cancer HCC1143 cell line were grown in RPMI-1640 medium with GlutaMAX (\#61870-010, Gibco) HEK293T cells, used for the production of lentiviral particles, and breast cancer Hs578T cell line were cultivated in DMEM with GlutaMAX (\#31966-021, Gibco) All the media were supplemented with $10 \%$ fetal bovine serum (FBS) (\#10270, Gibco), and the cells were grown at $37^{\circ} \mathrm{C}$ in a humidified atmosphere of $5 \% \mathrm{CO}_{2}$ and $95 \%$ air.

Plasmid construction and transfections. Stable knockdown of RPSAP52 was achieved with the following sequences: shRNA1 and shRNA4 target, respectively, the 5'TCCTTAAGCTCCTTGCAGT3' and 5'CACGGACTCTTAAGCAACA3' sequences of RPSAP52 mRNA (both located on the last exon), whereas shRNA3 targets the 5'GTGCAAGACTCAGGAGCTA3' sequence of RPSAP52 (on the first intron, which is inefficiently spliced). These shRNAs were expressed by cloning oligos shRPSAP52-1for and shRPSAP52-1rev (shRNA1), shRPSAP52-4for and shRPSAP52-4rev (shRNA4), and shRPSAP52-3for and shRPSAP52-3rev (shRNA3) into the BamHI and EcoRI sites of the vector pLVX-shRNA2 (Clontech). A scramble (scr) sequence was used as a control. For lentivirus-mediated depletion, HEK293T cells were transfected with pLVX-shRNA2-constructs plus packaging plasmids with jetPRIME ${ }^{\circledR}$ (Polyplus-transfection) according to the manufacturer's recommendations. The target cell line was infected with the supernatant containing viral particles $48 \mathrm{~h}$ post-transfection. ZsGreen 1 was used as a marker to visualize transductants by fluorescence microscopy, and these cells were selected by fluorescence-activated cell sorting (FACS) and plated to obtain stable clones. Antisense oligonucleotides (LNA ${ }^{\mathrm{m}}$ GapmeRs, \#300600, Exiqon) targeting HMGA2 mRNA (HMGA2), exon1 (RPSAP52 Ex) or the first intron (RPSAP52 RL1 and RL2) of RPSAP52 transcript were transfected to a final concentration of $65 \mathrm{nM}$ using HiPerfect (Qiagen). Cells were retransfected $48 \mathrm{~h}$ later and collected $72 \mathrm{~h}$ after the second round of LNA treatment. A control LNA GapmeR (\#300610, Exiqon) was used as mock transfection. For siRNA-mediated knockdown of LIN28B, cells were transfected with a 1:1 mix of two different siRNAs against LIN28B (\#216387-216388, Ambion) and a negative control (C-) (\#AM4611, Ambion), using Lipofectamine ${ }^{\mathrm{TM}}$ RNAiMAX Transfection Reagent 
(\#13778, Invitrogen) according to the manufacturer's recommendations. The overexpression of LIN28B was achieved with pcDNA3-FLAG-Lin28B (\#51373, Addgene), and we used pcDNA3.1 + (Invitrogen) as a control (empty) and jetPRIME $^{\circledR}$ (Polyplus-transfection) as the transfection reagent.

Transcription/translation assay. RPSAP52 full-length transcript (from RefSeq NR_026825 annotation) was amplified by PCR from A673 cDNA with oligos T7RPSAP52for-TnT and RPSAP52rev-TnT, producing two isoforms that include or exclude the alternative exon downstream of the T7 bacteriophage promoter. After gel purification, the PCR product was used directly in coupled transcription and translation reactions in reticulocyte extracts $\left(\mathrm{TNT}^{\circledR}{ }^{\circledR}\right.$ Quick Coupled Transcription/ Translation Systems, Promega), following the manufacturer's indications and by labeling the reactions with ${ }^{35} \mathrm{~S}$. The translation products were separated by SDS PAGE, the gel was then vacuum-dried and exposed overnight with an autoradiography film.

RNA isolation and RT-qPCR analysis. Total RNA, including miRNAs, was extracted using the Maxwell ${ }^{\circledR}$ RSC instrument with the Maxwell ${ }^{\circledast}$ RSC miRNA Tissue kit (Promega) according to the manufacturer's recommendations. For mRNA expression analysis, total RNA was reverse transcribed using the SuperScript ${ }^{\mathrm{TM}}$ III Reverse Transcriptase (\#18080, Invitrogen). Real-time PCR reactions were performed in triplicate in an Applied Biosystems 7900HT Fast Real-Time PCR system, using 30-100 ng cDNA, $6 \mu$ SYBR $^{\circledR}$ Green PCR Master Mix (Applied Biosystems), and $416 \mathrm{nM}$ primers in a final volume of $12 \mu \mathrm{l}$ for 384 -well plates. All data were acquired and analyzed with the QuantStudio Design \& Analysis Software v1.3.1 and normalized with respect to GUSB as endogenous control. Relative RNA levels were calculated using the comparative Ct method $(\Delta \Delta \mathrm{Ct})$. For miRNA expression analysis, miRCURY LNA ${ }^{\text {sx }}$ Universal RT microRNA PCR System (Exiqon) was used, according to the manufacturer's recommendations, with the Universal cDNA Synthesis Kit II (\#203301) for the RNA retrotranscription and the ExiLENT SYBR ${ }^{\circledast}$ Green master mix (\#203421) for the RT-qPCR in the LightCycler $^{\circledast} 480$ (Roche) with the LightCycler ${ }^{\circledast} 480$ Software v1.5.0 SP4. To normalize the data, $R N U 6 B$ or $m i R-195$ were used as endogenous control.

Actinomycin D treatment and RNA stability analysis. Control or RPSAP52 depleted A673 clones were treated with either $0.5 \%$ DMSO or $5 \mu \mathrm{g} \mathrm{ml}{ }^{-1}$ Actinomycin D (Sigma) for $9 \mathrm{~h}$. Pellets of each condition and treatment were harvested at different times and RNA was extracted for the RT-qPCR experiments. All data were normalized with respect to GUSB as endogenous control and gene expression fold-changes induced by Actinomycin $\mathrm{D}$ were calculated relative to the control (DMSO) cells of each condition and time point. c-FOS and GAPDH were used as controls of the experiment due to their short and long half-life, respectively.

SRB assay. Cell viability and proliferation were determined by the sulforhodamine $\mathrm{B}$ (SRB) assay. Cells were seeded in 96-well microplates in medium with $10 \% \mathrm{FBS}$, and the experiment started after $24 \mathrm{~h}$ of incubation at $37^{\circ} \mathrm{C}$ and $5 \% \mathrm{CO}_{2}$. The optimal cell number (100 cells per well for MCF10A and 2000 cells per well for Hs578T and HCC1143) was determined to ensure that the cells were in growth phase at the end of the assay. During 7 consecutive days, at least 6 wells per condition were processed as follows. The medium was removed and the cells were fixed with $10 \%$ trichloroacetic acid for $1 \mathrm{~h}$ at $4{ }^{\circ} \mathrm{C}$. Then, two washes with $1 \%$ acetic acid were performed and the viable cells were stained with $0.057 \%$ SRB in $1 \%$ acetic acid. Following $30 \mathrm{~min}$ of incubation at RT, the SRB was removed by washing twice with $1 \%$ acetic acid. The wells were air-dried completely and the SRB bound to the viable cells was dissolved with $100 \mu \mathrm{l}$ of Tris-HCl $10 \mathrm{mM}(\mathrm{pH} \mathrm{10.0)}$. Absorbance at $540 \mathrm{~nm}$ was determined on an automatized microtiter plate reader PowerWave XS (BioTek).

Colony formation assay. Cells were seeded into $35 \mathrm{~mm}$ dishes with three triplicates per condition at a density of 200 cells per plate for MCF10A and HCC1143 and 500 cells per plate for Hs578T. They were maintained for 8-15 days in a humidified incubator with $5 \% \mathrm{CO}_{2}$ at $37^{\circ} \mathrm{C}$. Cells were then fixed in $4 \%$ paraformaldehyde and stained with $0.5 \%$ crystal violet for $30 \mathrm{~min}$. Digital images were obtained using GBox (Syngene) and colonies containing more than 50 cells were counted manually using ImageJ v1.50 software. Plating efficiency and survival fractions were determined by using the following formulas:

Plating efficiency $=\frac{\text { number of colonies obtained }}{\text { number of cells seeded }}$
Surviving fraction $=\frac{\text { plating efficiency }}{\text { number of colonies obtained in the control condition }} \times 100$

Real-time migration assay. The xCELLigence Real-Time system (ACEA Biosciences) was used with CIM-16 plates of $8 \mu \mathrm{m}$ pore membranes. The lower chamber wells were filled with $160 \mu$ of medium containing $10 \%$ FBS and the top chamber wells with $40 \mu \mathrm{l}$ of serum-free medium. The two chambers were assembled together and allowed to equilibrate for $1 \mathrm{~h}$ at $37^{\circ} \mathrm{C}$ and $5 \% \mathrm{CO}_{2}$. Cells were incubated for $24 \mathrm{~h}$ in serum-free medium, rinsed with PBS, trypsinized and resuspended in medium supplemented with $10 \%$ FBS to inactivate the trypsin, followed by centrifugation and resuspension in serum-free medium. A total of $8 \times$ $10^{4}$ cells were seeded onto the top chamber of CIM-16 plates and placed into the xCELLigence system for data collection after background measurement. The software RTCA 2.0 was set to collect impedance data every $15 \mathrm{~min}$. The cell index represents the capacity for cell migration, whereas the slope of the curve can be related to the cell invasion ability.

Transwell migration assay. Transwell ${ }^{\oplus}$ Permeable Supports (\#3422, Cultek) with $8 \mu \mathrm{m}$ pore polycarbonate membranes in 24 -well plates were used to measure cell migration. Cells were incubated for $24 \mathrm{~h}$ in serum-free medium, rinsed with PBS, trypsinized, and resuspended in $10 \%$ FBS-containing medium to inactivate the trypsin, followed by centrifugation and resuspension in serum-free medium. A total of $1 \times 10^{5}$ cells were seeded onto each transwell with $150 \mu \mathrm{l}$ of serum-free medium and the transwells were placed in the wells of a 24 -well plate with $500 \mu \mathrm{l}$ of $10 \%$ FBS-containing medium. The chemoattractant promoted the migration of the cells from the upper part of the transwell to the lower part. After $24 \mathrm{~h}$ of incubation at $37^{\circ} \mathrm{C}$ and $5 \% \mathrm{CO}_{2}$, the cells in the upper part of the membrane were removed with a cotton swab and several washes with $1 \times$ PBS. Cells in the lower part were fixed for $10 \mathrm{~min}$ with ice-cold $100 \%$ methanol. For the staining, cells were covered with $0.5 \%$ crystal violet in $25 \%$ methanol for $10 \mathrm{~min}$. Transwells were washed several times with $1 \times$ PBS and air-dried. Membranes were then mounted on a slide for image acquisition.

Clonogenicity assay. The clonogenicity of RPSAP52-depleted MCF10A clones was tested in soft agar by using the CytoSelect 96-well Cell Transformation Assay Kit (Cell Biolabs, \#CBA-130), following the manufacturer's instructions. Briefly, a base agar layer was prepared by mixing equal volumes of $1.2 \%$ agar solution and $2 \times$ DMEM/20\%FBS medium in each well of a 96-well flat-bottom microplate. In total, 5000 cells per well were seeded in a top layer by mixing equal volumes of the cell suspension, $1.2 \%$ agar solution and $2 \times$ DMEM/20\%FBS (1:1:1), and incubated for 6 days after covering the solidified cell agar layer with $100 \mu \mathrm{l}$ of DMEM-F12 medium plus supplements. The CyQuant GR dye was used to detect the lysed colonies and the proportional fluorescence to the number and size of colonies was read using a PerkinElmer's VICTOR X5 multilabel plate reader with a 485/535 filter set and $1 \mathrm{~s}$ of measurement time. The data are expressed in relative fluorescence units (RFU).

In vivo xenograft. Athymic nude female mice (Charles River, Inc (USA), strain Crl:NU(NCr)-Foxlnu) were subcutaneously injected at 7-8 weeks of age in one flank with a total of $10 \times 10^{6} \mathrm{MCF} 10 \mathrm{~A}, 7 \times 10^{6} \mathrm{~A} 673$, and $5 \times 10^{5} \mathrm{Hs} 578 \mathrm{~T}$ cells from clones expressing either scrambled or RPSAP52-shRNAs, soaked in $100 \mu \mathrm{l}$ of Matrigel (BD Biosciences). Tumor growth was monitored every 7 days for MCF10A, 3-4 days for A673, and 4 days for Hs578T by measuring tumor width $(W, \mathrm{~mm})$ and length $(L, \mathrm{~mm})$ until mice were killed at the indicated days postinjection. After allowing to grow for several weeks, tumor volume $\left(V, \mathrm{~mm}^{3}\right)$ was estimated from the formula $V=\frac{\pi \times L \times W^{2}}{6}$ and tumor weight (g) measured. Animal tests complied with ethical regulations. All the mouse experiments were approved by IDIBELL's Committee for Animal Experimentation.

Absolute quantification. Estimations of the absolute amounts of RNAs were obtained by comparison with in vitro transcribed RNA standards of known concentration. These RNA standards correspond to the sequences amplified in RTqPCR in the analysis of RPSAP52 + altex, RPSAP52 - altex, HMGA2 and LIN28B transcript expression in all figures, and were generated by introducing the T7 RNA Polymerase promoter upstream of the amplicon by PCR and subsequent in vitro transcription. Serial dilutions of the synthesized RNA standards were used as spikeins in total RNA extractions from MCF7 cells (which do not express any of the transcripts of interest) and processed in parallel in RT-qPCR with RNA extractions from a known number of MCF10A or A673 cells, so that transcript copy number per cell could be measured. Similarly, for determination of let-7 copy number, we generated a standard curve using synthetic let-7a, $b$ and $e$ purified RNA oligonucleotides (Sigma), corresponding to the sequences hsa-let-7a-5p (5'-rUrGrArGrGrUrArGrUrArGrGrUrUrGrUrArUrArGrUrU-3'), hsa-let-7b-5p (5'-r

UrGrArGrGrUrArGrUrArGrUrUrGrUrGrUrGrGrUrU-3'), and hsa-let-7e-5p (5'rUrGrArGrGrUrArGrGrArGrGrUrUrGrUrArUrArGrUrU-3'). For protein quantification, total extracts from a recorded number of cells was analyzed by western blot in parallel with known amounts of the following recombinant proteins: LIN28B (ab134596, Abcam), IGF2BP2 (ab153107, Abcam), HNRNPQ (ab153089, Abcam). Western blot was performed with the following antibodies: anti-LIN28B (ab71415, Abcam, 1:1000), anti-IGF2BP2 (H00010644-M01, Abnova, 1:500), antiHNRNPQ (NBP1-57197, Novus Biologicals, 1:1000). Band intensity was measured by densitometry with an iBright ${ }^{\mathrm{Tm}}$ CL1000 Imaging System (ThermoFisher).

iCLIP-seq. iCLIP-seq was performed on stable A673 clones. Approximately $8 \times 10^{6}$ A673 cells stably expressing scrambled shRNA (scr) or shRNA-4 against RPSAP52 (clone B11) were crosslinked with $150 \mathrm{~mJ} \mathrm{~cm}^{-2}$ total 254-nm irradiation in a Stratalinker 2400. The same amount of non-crosslinked cells were used as controls.

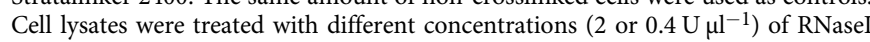


(\#AM2294, ThermoFisher) and $4 \mathrm{U}$ of Turbo DNase (\#AM2238, ThermoFisher) in a final volume of $1 \mathrm{ml}$. Lysates were then cleared and immunoprecipitated overnight at $4{ }^{\circ} \mathrm{C}$ with $10 \mu \mathrm{g}$ of anti-IGF2BP2 antibody (\#RN008P, MBL) preincubated for $1 \mathrm{~h}$ at room temperature with $60 \mu \mathrm{l}$ anti-rabbit IgG Dynabeads (\#11204D, ThermoFisher). After two washes in high-salt buffer (50 mM Tris- $\mathrm{HCl} \mathrm{pH} \mathrm{4.4,} 1 \mathrm{M}$ $\mathrm{NaCl}, 1 \mathrm{mM}$ EDTA, 1\% Igepal CA-630, 01\% SDS, 0.5\% sodium deoxycholate) and one wash in PNK buffer (20 mM Tris- $\mathrm{HCl} \mathrm{pH} \mathrm{7.4,} 10 \mathrm{mM} \mathrm{MgCl}_{2}, 0.2 \%$ Tween-20), RNA $3^{\prime}$ end was dephosphorylated with PNK for $20 \mathrm{~min}$ at $37^{\circ} \mathrm{C}$. Beads were then washed once with PNK buffer, once with high-salt buffer and twice with PNK buffer. L3 adapter was then ligated overnight at $16^{\circ} \mathrm{C}$ in a $20 \mu \mathrm{l}$ reaction containing $1.5 \mu \mathrm{M}$ pre-adenylated L3-App adapter (rAppAGATCGGAAGAGCGGTTCAG// ddC/), $4 \mu \mathrm{l}$ PEG400 and $10 \mathrm{U}$ T4 RNA Ligase1 (\#M0204, New England Biolabs). Beads were then washed twice with high-salt buffer and twice with PNK buffer, and $20 \%$ of beads were radioactively labeled with $\gamma$-[32 P]-ATP and $0.5 \mathrm{U} \mathrm{\mu l}^{-1}$ PNK (\#M0201, New England Biolabs) for $5 \mathrm{~min}$ at $37^{\circ} \mathrm{C}$, added to the remaining cold beads and incubated in $20 \mu \mathrm{l} 1 \mathrm{xNuPAGE}$ buffer for $5 \mathrm{~min}$ at $70^{\circ} \mathrm{C}$ prior to loading the supernatant on a $4-12 \%$ NuPAGE Bis-Tris gel (\#NP0341BOX, ThermoFisher). The gel was run at $180 \mathrm{~V}$ for $50 \mathrm{~min}$, and the protein-RNA complexes were transferred to a nitrocellulose membrane at $30 \mathrm{~V}$ for $1 \mathrm{~h}$. The membrane was then autoradiographed through exposure to a film at $-80^{\circ} \mathrm{C}$ for $1 \mathrm{~h}$. Regions of interest containing the IGF2BP2-RNA crosslinked products were cut out of the membrane and the RNA fragments isolated, reverse transcribed, purified and circularized by incubating with CircLigase II (Epicentre) for $1 \mathrm{~h}$ at $60^{\circ} \mathrm{C}$, followed by annealing to Cut_oligo (5'-GTTCAGGATCCACGACGCTCTTCAAAA-3') and digestion with BamHI. iCLIP libraries were amplified for 27 cycles with P3/P5 Solexa primers, and the appropriate size of products were confirmed by gel electrophoresis. Sequencing of the libraries was performed on a MiSeq instrument following standard manufacturer's procedures, using MiSeq Reagent Kit v3 reagents with single-read, 151bases read profile. Two independent experiments were performed for each condition. The four libraries were sequenced in two separated pools (\#31 \& \#38) and data acquired with MiSeq Reporter v2.6.3.2. Raw data can be downloaded from https://www.ncbi.nlm.nih.gov/sra/?term=PRJNA484688.

iCLIP computational analysis. Read quality was assessed using FastQC (v0.11.7) software (available online at http://www.bioinformatics.babraham.ac.uk/projects/ fastqc). After sequencing, PhiX sequences were removed using BWA (BurrowsWheeler Aligner, v0.7.17) ${ }^{67}$. All the pre-processing steps, peak calling, CITS calling, and annotations were performed using CTK (CLIP Tool Kit) (v1.0.9) software68, following the recommendations found in https://zhanglab.c2b2.columbia.edu/ index.php/ICLIP_data_analysis_using_CTK. After pre-processing steps, final tags from the two biological replicates of the same condition were merged to proceed with peak and CITS calling steps. Peak calling was statistically assessed using a Bonferroni adjusted $P$-value $<0.05$ as a significance threshold. For CITS calling, all tags presenting substitutions were excluded from the analysis, since the abnormally high frequency of substitutions observed could be due to reverse transcriptase readthrough. CITS were considered significant with a $P$-value $<0.001$. No proximity clustering was applied in either of the analysis. Adapter trimming, sequence alignments, and alignment manipulations were performed using Cutadapt (v1.16), BWA and samtools (v1.8), respectively. All genome alignments and annotations used hg19 human genome (GCA_000001405.1) as a reference. De novo motif discovery from CITS was performed using HOMER (v4.10) software ${ }^{69}$, for which a window of CITS $+/-10$ nucleotides was taken. Additional python scripts were used for specific CAUH motif enrichment analysis. Genome Browser images were generated using Golden Helix GenomeBrowse ${ }^{\circledast}$ v3.0.0 software (available from http://www.goldenhelix.com). Let-7a/b/e predicted target genes, used for let-7 enrichment analysis in the obtained peaks, were downloaded from miRDB (http:// www.mirdb.org/). For differential binding analysis, $3^{\prime}$ UTR tags obtained after preprocessing steps by CTK software were used to generate $3^{\prime}$ UTR tag counts for each biological replicate of the two conditions. Using these counts, differential binding analysis was performed using DESeq2 bioconductor package v1.18.170. Gene enrichment analyses from significant peaks were conducted using Enrichr v2.0 software (http://amp.pharm.mssm.edu/Enrichr/) (11,72 $^{\text {Additional graphics and }}$ statistical analysis were performed using R v3.4.3 programming language (https:// www.R-project.org/).

Primary tumors expression and methylation analysis. RNA expression and DNA methylation data from different tumor types was collected from The Cancer Genome Atlas (TCGA) Data Portal (https://tcga-data.nci.nih.gov/tcga). TCGA data were downloaded using TCGAbiolinks v2.9.2 $2^{73}$. Bioconductor package from the current GDC (Genomic Data Commons) harmonized database aligned against hg38 genome. Box plots analysis represent normalized expression and methylation values corresponding to TCGA COAD, LUSC, LUAD, THCA, and BRCA projects from the GDC data portal (https://portal.gdc.cancer.gov/). We use the Wilcoxon signed-rank test to compare differences between groups. The association between HMGA2 and RPSAP52 expression in primary tumors and cell lines was estimated with a Pearson's correlation. All the statistical analysis and graphical representations were performed using R v3.4.3. For primary samples, an average of HMGA2/ RPSAP52 promoter methylation $>0.26$ (median of the population) was considered as hypermethylated. NCI60 cell lines expression data were downloaded from cBioPortal database (http://www.cbioportal.org/).
Polysome profile analysis. MCF10A cells or A673 stable clones were plated in $150 \mathrm{~mm}$ dishes and treated with $100 \mathrm{\mu g} \mathrm{ml}^{-1}$ cycloheximide (CHX) at $37^{\circ} \mathrm{C}$ for $5 \mathrm{~min}$. Cells were washed twice with cold PBS supplemented with CHX, pelleted and resuspended in $250 \mu \mathrm{l}$ of hypotonic lysis buffer $\left(1.5 \mathrm{mM} \mathrm{KCl}, 2.5 \mathrm{mM} \mathrm{MgCl}_{2}\right.$, $5 \mathrm{mM}$ Tris-HCl pH 7.4, $1 \mathrm{mM}$ DTT, $1 \%$ sodium deoxycholate, $1 \%$ Triton X-100, $100 \mu \mathrm{g} \mathrm{ml}^{-1} \mathrm{CHX}$ ) supplemented with mammalian protease inhibitors (SIGMA) and RNase inhibitor (NEB) at a concentration of $100 \mathrm{U} \mathrm{ml}^{-1}$, and left on ice for 5 min. Cell lysates were cleared of debris and nuclei by centrifugation for $5 \mathrm{~min}$ at $17,000 \times g$. Protein concentrations were determined by BCA assay and $500 \mu \mathrm{g}$ of lysate were loaded on $10-50 \%$ sucrose linear gradients containing $80 \mathrm{mM} \mathrm{NaCl}$, $5 \mathrm{mM} \mathrm{MgCl} 2,20 \mathrm{mM}$ Tris-HCl pH 7.4, $1 \mathrm{mM}$ DTT, $10 \mathrm{U} \mathrm{ml}^{-1}$ RNase inhibitor with a BIOCOMP gradient master. Gradients were centrifuged on a SW40 rotor for $3.5 \mathrm{~h}$ at $217,290 \times \mathrm{g}$. Gradients were analyzed on a BIOCOMP gradient station and collected in 11 (MCF10A) or 13 (A673) fractions ranging from light to heavy sucrose. Fractions were supplemented with SDS at a final concentration of $1 \%$ and placed for $10 \mathrm{~min}$ at $65^{\circ} \mathrm{C}$. To each fraction was added $1 \mathrm{ng}$ of firefly luciferase mRNA, followed by phenol-chloroform extraction and precipitation with isopropanol. Purified RNAs from each fraction were retrotranscribed and subjected to qPCR. mRNA quantification was normalized to firefly mRNA.

IGF2BP2 coimmunoprecipitation and mass spectrometry analysis. Immunoprecipitation and sample digestion for mass spectrometry analysis: $1 \mathrm{mg}$ of precleared protein extract from three replicates of control cells (scr) and cells depleted for RPSAP52 (sh4 B11 clone) were immunoprecipitated overnight at $4{ }^{\circ} \mathrm{C}$ using $5 \mu \mathrm{g}$ of anti-IGF2BP2 antibody (\#H00010644-M01, Abnova) and $40 \mu \mathrm{l}$ of Dynabeads ${ }^{\oplus}$ M-280 anti-mouse IgG beads (\#11202D, ThermoFisher) in $1 \mathrm{ml}$ RIP buffer $(150 \mathrm{mM} \mathrm{KCl}, 25 \mathrm{mM}$ Hepes at pH 7.9, $5 \mathrm{mM}$ EDTA, $0.5 \mathrm{mM}$ DTT, 0.5\% NP40, $1 \times$ protease inhibitor cocktail (Roche)). After three washes with RIP buffer, the resulting material was in-bead digested with trypsin. Briefly, the beads were washed three times with $500 \mathrm{ml}$ of $200 \mathrm{mM}$ Ammonium Bicarbonate (ABC) and resuspended in $60 \mathrm{ml}$ of $6 \mathrm{M}$ Urea $200 \mathrm{mM}^{-1} \mathrm{ABC}$. The samples were then reduced with $10 \mathrm{ml}$ of $10 \mathrm{mM}$ DTT $\left(1 \mathrm{~h}, 30^{\circ} \mathrm{C}\right)$ and alkylated with $10 \mathrm{ml}$ of $20 \mathrm{mM}$ Iodoacetamide ( $30 \mathrm{~min}$, room temperature and darkness). After that, the samples were diluted with $280 \mathrm{ml}$ of $200 \mathrm{mM} \mathrm{ABC}$ and digested with $5 \mathrm{ml}$ of $0.2 \mathrm{mg} \mathrm{ml}^{-1}$ Trypsin for $16 \mathrm{~h}$ at $37^{\circ} \mathrm{C}$. The beads were finally pulled down ( $5 \mathrm{~min}$ at $5000 \mathrm{~g}$ ), the supernatant transferred to new, cleaned tubes and acidified with $20 \mathrm{ml}$ of $100 \%$ Formic acid. The resulting peptides mixtures were desalted using C18 stage tips (UltraMicroSpin Column, The Nest Group, Inc., MA) and dried in a SpeedVac.

Mass spectrometry analysis (LC-MS/MS): the dried-down peptide mixtures were analyzed in a nanoAcquity liquid chromatographer (Waters) coupled to a LTQ-OrbitrapVelos (ThermoScientific) mass spectrometer. The tryptic digests were resuspended in $10 \mu \mathrm{l}$ \% FA solution and an aliquot of $3 \mu \mathrm{l}$ of each sample was injected for chromatographic separation. Peptides were trapped on a Symmetry C18TM trap column $(5 \mu \mathrm{m}, 180 \mu \mathrm{m} \times 20 \mathrm{~mm}$; Waters), and were separated using a C18 reverse phase capillary column (ACQUITY UPLC BEH column; $130 \AA$, $1.7 \mu \mathrm{m}, 75 \mu \mathrm{m} \times 250 \mathrm{~mm}$, Waters). Eluted peptides were subjected to electrospray ionization in an emitter needle (PicoTipTM, New Objective) with an applied voltage of $2000 \mathrm{~V}$. Peptide masses $(300-1700 \mathrm{~m} / \mathrm{z})$ were analyzed in data dependent mode, where a full scan MS was acquired in the Orbitrap with a resolution of $60,000 \mathrm{FWHM}$ at $400 \mathrm{~m} / \mathrm{z}$. Up to the 15th most abundant peptides (minimum intensity of 500 counts) were selected from each MS scan and then fragmented in the linear ion trap using CID (38\% normalized collision energy) with helium as the collision gas. The scan time settings were Full MS: $250 \mathrm{~ms}$ (1 microscan) and MSn: $120 \mathrm{~ms}$. Generated raw data files were collected with ThermoXcalibur (v2.2).

Data analysis: the .raw files were analyzed with the MaxQuant(v.1.6.2.6a) software using the built-in search engine Andromeda to search against the Swissprot Human database downloaded from UniprotKB website in March 26 2018. The search parameters were set as follow: the enzyme was trypsin with a maximum of two allowed missed cleavages. Oxidation in methionines as well as Acetylation at protein $\mathrm{N}$-terminal was set as variable modifications while carbamidomethylation in cysteines was set as fixed modification. The mass tolerances for the first and main search were set at 20 and $4.5 \mathrm{ppm}$, respectively. In addition, only peptides with more than 6 and up to 25 aminoacids were considered. The final list of identified peptides and proteins were filtered by using a $5 \%$ false discovery rate (FDR) both at peptide and protein level. To enhance the identification of proteins the match between runs option was selected.

Protein-protein interaction analysis: the statistical analysis of the protein-protein interactions found in our experimental conditions was performed with the help of the Significance Analysis of the INTeractome (SAINT) algorithm which was implemented in the http://statsms.crg.es/ site.

Expression arrays. Total RNA from each sample was quantified using the NanoDrop ND-1000 and RNA integrity was assessed by standard denaturing agarose gel electrophoresis. For microarray analysis, Agilent Array platform was employed. The sample preparation and microarray hybridization were performed based on the manufacturer's standard protocols. Briefly, total RNA from each sample was amplified and transcribed into fluorescent cRNA with using the manufacturer's Agilent's Quick Amp Labeling protocol (version 5.7, Agilent Technologies). The labeled cRNAs were hybridized onto the Whole Human Genome Oligo Microarray $(4 \times 44 \mathrm{~K}$, Agilent Technologies). After having washed 
the slides, the arrays were scanned by the Agilent Scanner G2505C. Agilent Feature Extraction software (version 11.0.1.1) was used to analyze acquired array images. Quantile normalization and subsequent data processing were performed using the GeneSpring GX v12.1 software (Agilent Technologies). Differentially expressed genes were identified through Fold Change filtering and Volcano filtering. Pathway analysis and GO Analysis were applied to determine the roles of these differentially expressed genes.

Statistical analysis. Bar graphics and statistical comparisons were obtained with the GraphPad Prism 8.1.2 software. Comparative analyses between different experimental groups were performed using $t$-student test and one-way ANOVA with Bonferroni's or Dunnet's post hoc tests for intergroup comparisons. For cancer patients' samples, we used the Kaplan-Meier method for survival analysis and the log-rank test was used to analyze the differences between the groups. Cox regression method was used to analyze the independent prognostic importance of expression or methylation. Results of the univariate Cox regression analysis are represented by the hazards ratio (HR) and $95 \%$ confidence interval (CI). Results were considered significant if the $P$-value was $<0.05\left({ }^{*}\right),<0.01\left({ }^{* *}\right),<0.001\left({ }^{* *}\right)$, or $<0.0001\left(^{* * * *}\right)$. Unless otherwise stated, data are presented as the mean \pm SD.

Unprocessed scans. All unprocessed and uncropped scans and images can be found in the source data file.

\section{Data availability}

All relevant data are available from the authors. Raw data for the iCLIP-seq experiment have been deposited under the accession code PRJNA484688 (https://www.ncbi.nlm.nih. gov/sra/?term=PRJNA484688). iCLIP-seq peaks and CITS are provided in the OliveiraMateos et al_Supplementary Data 1. The list of significant altered transcripts from the microarray expression analysis is provided in the Oliveira-Mateos et al_Supplementary Data 2. Numerical source data for Figs. 1e-g, 2c, e, 3a-c, e-g, 4b, d, f, 5a, c, 6a-e, 7b; Supplementary Figs. 1c, 2b-e, 3c, d, f-h, d-f, 5g, j, 6a, c and $7 b$ and all unprocessed images and scans for Figs. 1d, f, 2a, b, d, f, g, 3d, f, g, 4b, c, e, 5a-c, 6f; Supplementary Figs. $2 \mathrm{a}, 3 \mathrm{e}-\mathrm{h}, 4 \mathrm{~d}, 5 \mathrm{a}, \mathrm{e}, \mathrm{h}, \mathrm{i}$, and $6 \mathrm{~b}$ can found in the source data file.

Received: 29 August 2018 Accepted: 8 August 2019

Published online: 04 September 2019

\section{References}

1. Djebali, S. et al. Landscape of transcription in human cells. Nature 489 , 101-108 (2012).

2. Engreitz, J. M., Ollikainen, N. \& Guttman, M. Long non-coding RNAs: spatial amplifiers that control nuclear structure and gene expression. Nat. Rev. Mol. Cell. Biol. 17, 756-770 (2016).

3. Délas, M. J. \& Hannon, G. J. LncRNAs in development and disease: from functions to mechanisms. Open Biol. 7, 170121 (2017).

4. Di Gesualdo, F., Capaccioli, S. \& Lulli, M. A pathophysiological view of the long non-coding RNA world. Oncotarget 5, 10976-10996 (2014).

5. Holdt, L. M. et al. Alu elements in ANRIL non-coding RNA at chromosome 9p21modulate atherogenic cell functions through trans-regulation of gene networks. PloS Genet 9, e1003588 (2013).

6. Huarte, M. et al. A large intergenic noncoding RNA induced by p53 mediates global gene repression in the p53 response. Cell 142, 409-419 (2010).

7. Ying, L. et al. Downregulated MEG3 activates autophagy and increases cell proliferation in bladder cancer. Mol. Biosyst. 9, 407-411 (2013).

8. Panzitt, K. et al. Characterization of HULC, a novel gene with striking upregulation in hepatocellular carcinoma, as noncoding RNA. Gastroenterology 132, 330-342 (2007).

9. Arun, G. et al. Differentiation of mammary tumors and reduction in metastasis upon Malat1 lncRNA loss. Genes Dev. 30, 34-51 (2016).

10. Gupta, R. A. et al. Long non-coding RNA HOTAIR reprograms chromatin state to promote cancer metastasis. Nature 464, 1071-1076 (2010).

11. Fu, X., Ravindranath, L., Tran, N., Petrovics, G. \& Srivastava, S. Regulation of apoptosis by a prostate-specific and prostate cancer-associated noncoding gene, PCGEM1. DNA Cell Biol. 25, 135-141 (2006).

12. Venteicher, A. S. et al. A human telomerase holoenzyme protein required for Cajal body localization and telomere synthesis. Science 323, 644-648 (2009).

13. Yu, T. Y., Kao, Y. W. \& Lin, J. J. Telomeric transcripts stimulate telomere recombination to suppress senescence in cells lacking telomerase. Proc. Natl Acad. Sci. USA 111, 3377-3382 (2014).

14. Achour, C. \& Aguilo, F. Long non-coding RNA and Polycomb: an intricate partnership in cancer biology. Front. Biosci. 23, 2106-2132 (2018).

15. Kopp, F. \& Mendell, J. T. Functional classification and experimental dissection of long noncoding RNAs. Cell 172, 393-407 (2018).
16. Li, J. H., Liu, S., Zhou, H., Qu, L. H. \& Yang, J. H. starBase v2.0: decoding miRNA-ceRNA, miRNA-ncRNA and protein-RNA interaction networks from large-scale CLIP-seq data. Nucleic Acids Res. 42, D92-D97 (2014).

17. $\mathrm{Wu}, \mathrm{Q}$. et al. Analysis of the miRNA-mRNA-lncRNA networks in ER+ and ER- breast cancer cell lines. J. Cell. Mol. Med. 19, 2874-2887 (2015).

18. Arun, K. et al. Comprehensive analysis of aberrantly expressed lncRNAs and construction of ceRNA network in gastric cancer. Oncotarget 9, 18386-18399 (2018).

19. Johnsson, P., Morris, K. V. \& Grandér, D. Pseudogenes: a novel source of trans-acting antisense RNAs. Methods Mol. Biol. 1167, 213-226 (2014)

20. Poliseno, L. et al. A coding-independent function of gene and pseudogene mRNAs regulates tumour biology. Nature 465, 1033-1038 (2010).

21. Wend, $P$. et al. WNT10B/ $\beta$-catenin signalling induces HMGA2 and proliferation in metastatic triple-negative breast cancer. EMBO Mol. Med. 5 264-279 (2013).

22. Mahajan, A. et al. HMGA2: a biomarker significantly overexpressed in high grade ovarian serous carcinoma. Mod. Pathol. 23, 673-681 (2010).

23. Boque-Sastre, R. et al. Head-to-head antisense transcription and R-loop formation promotes transcriptional activation. Proc. Natl Acad. Sci. USA 112, 5785-5790 (2015).

24. Iyer, M. K. et al. The landscape of long noncoding RNAs in the human transcriptome. Nat. Genet. 47, 199-208 (2015).

25. Wu, J. et al. Elevated HMGA2 expression is associated with cancer aggressiveness and predicts poor outcome in breast cancer. Cancer Lett. 376, 284-292 (2016)

26. Yisraeli, J. K. VICKZ proteins: a multi-talented family of regulatory RNAbinding proteins. Biol. Cell. 97, 87-96 (2005).

27. Degrauwe, N., Suvà, M. L., Janiszewska, M., Riggi, N. \& Stamenkovic, I. IMPs: an RNA-binding protein family that provides a link between stem cell maintenance in normal development and cancer. Genes Dev. 30, 2459-2474 (2016).

28. Hafner, M. et al. Transcriptome-wide identification of RNA-binding protein and microRNA target sites by PAR-CLIP. Cell 141, 129-141 (2010).

29. Cleynen, I. et al. HMGA2 regulates transcription of the Imp2 gene via an intronic regulatory element in cooperation with nuclear factor-kappaB. Mol. Cancer Res. 5, 363-372 (2007).

30. Li, Z. et al. An HMGA2-IGF2BP2 axis regulates myoblast proliferation and myogenesis. Dev. Cell 23, 1176-1188 (2012).

31. $\mathrm{Li}, \mathrm{Z}$. et al. Oncogenic NRAS, required for the pathogenesis of embryonic rhabdomyosarcoma, relies upon the HMGA2-IGF2BP2 pathway. Cancer Res. 73, 3041-3050 (2013).

32. Busch, B. et al. The oncogenic triangle of HMGA2, LIN28B and IGF2BP1 antagonizes tumor-suppressive actions of the let-7 family. Nucleic Acids Res. 44, 3845-3864 (2016).

33. Degrauwe, N. et al. The RNA binding protein IMP2 preserves glioblastoma stem cells by preventing let-7 target gene silencing. Cell Rep. 15, 1634-1647 (2016).

34. Heo, I. et al. TUT4 in concert with Lin 28 suppresses microRNA biogenesis through pre-microRNA uridylation. Cell 138, 696-708 (2009).

35. Piskounova, E. et al. Lin28A and Lin28B inhibit let-7 microRNA biogenesis by distinct mechanisms. Cell 147, 1066-1079 (2011).

36. Viswanathan, S. R. et al. Lin 28 promotes transformation and is associated with advanced human malignancies. Nat. Genet. 41, 843-848 (2009).

37. Nielsen, J. et al. A family of insulin-like growth factor II mRNA-binding proteins represses translation in late development. Mol. Cell. Biol. 19, 1262-1270 (1999)

38. Dai, N. et al. IGF2 mRNA binding protein-2 is a tumor promoter that drives cancer proliferation through its client mRNAs IGF2 and HMGA1. eLife 6, e27155 (2017)

39. Gong, C. et al. A long non-coding RNA, LncMyoD, regulates skeletal muscle differentiation by blocking IMP2-mediated mRNA translation. Dev. Cell. $\mathbf{3 4}$ 181-191 (2015)

40. Conway, A. E. et al. Enhanced CLIP uncovers IMP protein-RNA targets in human pluripotent stem cells important for cell adhesion and survival. Cell Rep. 15, 666-679 (2016).

41. Scotlandi, K. et al. Overcoming resistance to conventional drugs in Ewing sarcoma and identification of molecular predictors of outcome. J. Clin. Oncol. 27, 2209-2216 (2009)

42. Hong, S. H. et al. High neuropeptide Y release associates with Ewing sarcoma bone dissemination-in vivo model of site-specific metastases. Oncotarget 6, 7151-7165 (2015)

43. Kainov, Y. et al. CRABP1 provides high malignancy of transformed mesenchymal cells and contributes to the pathogenesis of mesenchymal and neuroendocrine tumors. Cell Cycle 13, 1530-1539 (2014).

44. Zaugg, K. et al. Carnitine palmitoyltransferase $1 \mathrm{C}$ promotes cell survival and tumor growth under conditions of metabolic stress. Genes Dev. 25, 1041-1051 (2011). 
45. Emori, M. et al. High expression of CD109 antigen regulates the phenotype of cancer stem-like cells/cancer-initiating cells in the novel epithelioid sarcoma cell line ESX and is related to poor prognosis of soft tissue sarcoma. PloS One 8, e84187 (2013)

46. Fujikawa, A. et al. Targeting PTPRZ inhibits stem cell-like properties and tumorigenicity in glioblastoma cells. Sci. Rep. 7, 5609 (2017).

47. Zeleniak, A. E., Huang, W., Brinkman, M. K., Fishel, M. L. \& Hill, R. Loss of MTSS1 results in increased metastatic potential in pancreatic cancer. Oncotarget 8, 16473-16487 (2017).

48. Agarwal., E. et al. Role of Akt2 in regulation of metastasis suppressor 1 expression and colorectal cancer metastasis. Oncogene 36, 3104-3118 (2017).

49. Zhang, X. et al. Interrogation of nonconserved human adipose lincRNAs identifies a regulatory role of $l i n c-A D A L$ in adipocyte metabolism. Sci. Transl. Med. 10, eaar5987 (2018).

50. Hosen, M. R. et al. Airn regulates Igf $2 \mathrm{bp} 2$ translation in cardiomyocytes. Circ. Res. 122, 1347-1353 (2018).

51. Mineo, M. et al. The long non-coding RNA HIF1A-AS2 facilitates the maintenance of mesenchymal glioblastoma stem-like cells in hypoxic niches. Cell Rep. 15, 2500-2509 (2016).

52. Jønson, L. et al. IMP3 RNP safe houses prevent miRNA-directed HMGA2 mRNA decay in cancer and development. Cell Rep. 7, 539-551 (2014).

53. Chatterjee, S., Fasler, M., Büssing, I. \& Grosshans, H. Target-mediated protection of endogenous microRNAs in C.elegans. Dev. Cell. 20, 388-396 (2011).

54. Pitchiaya, S., Heinicke, L. A., Park, J. I., Cameron, E. L. \& Walter, N. G. Resolving subcellular miRNA trafficking and turnover at single-molecule resolution. Cell Rep. 19, 630-642 (2017).

55. Boyerinas, B. et al. Identification of let-7-regulated oncofetal genes. Cancer Res. 68, 2587-2591 (2008).

56. Rybak, A. et al. A feedback loop comprising lin-28 and let-7 controls pre-let-7 maturation during neural stem-cell commitment. Nat. Cell. Biol. 10, 987-993 (2008).

57. Viswanathan, S. R., Daley, G. Q. \& Gregory, R. I. Selective blockade of microRNA processing by Lin28. Science 320, 97-100 (2008).

58. Nair., V. S., Maeda, L. S. \& Ioannidis, J. P. Clinical outcome prediction by microRNAs in human cancer: a systematic review. J. Natl. Cancer Inst. 104, 528-540 (2012).

59. Kugel, S. et al. SIRT6 suppresses pancreatic cancer through control of Lin28b. Cell 165, 1401-1415 (2016).

60. Chien, C. S. et al. Lin28B/Let-7 regulates expression of Oct4 and Sox 2 and reprograms oral squamous cell carcinoma cells to a stem-like state. Cancer Res. 75, 2553-2565 (2015).

61. Akao, Y., Nakagawa, Y. \& Naoe, T. Let-7 microRNA functions as a potential growth suppressor in human colon cancer cells. Biol. Pharm. Bull. 29, 903-906 (2006).

62. Damanakis, A. I. et al. MicroRNAs let7 expression in thyroid cancer: correlation with their deputed targets HMGA2 and SLC5A5. J. Cancer Res. Clin. Oncol. 142, 1213-1220 (2016).

63. Peng, F. et al. H19/let-7/LIN28 reciprocal negative regulatory circuit promotes breast cancer stem cell maintenance. Cell Death Dis. 8, e2569 (2017).

64. Feng, S. et al. Expression and functional role of reprogramming-related long noncoding RNA (lincRNA-ROR) in glioma. J. Mol. Neurosci. 56, 623-630 (2015).

65. Kallen, A. N. et al. The imprinted H19 IncRNA antagonizes let-7 microRNAs. Mol. Cell 52, 101-112 (2013).

66. Sgarra, R. et al. High mobility group A (HMGA) proteins: molecular instigators of breast cancer onset and progression. Biochim. Biophys. Acta 1869, 216-229 (2018).

67. Li, H. \& Durbin, R. Fast and accurate long-read alignment with BurrowsWheeler transform. Bioinformatics 26, 589-595 (2010).

68. Shah, A., Qian, Y., Weyn-Vanhentenryck, S. M. \& Zhang, C. CLIP Tool Kit (CTK): a flexible and robust pipeline to analyze CLIP sequencing data. Bioinformatics 33, 566-567 (2017).

69. Heinz, S. et al. Simple combinations of lineage-determining transcription factors prime cis-regulatory elements required for macrophage and B cell identities. Mol. Cell 38, 576-589 (2010).

70. Love, M. I., Huber, W. \& Anders, S. Moderated estimation of fold change and dispersion for RNA-seq data with DESeq2. Genome Biol. 15, 550 (2014).
71. Chen, E. Y. et al. Enrichr: interactive and collaborative HTML5 gene list enrichment analysis tool. BMC Bioinforma. 14, 128 (2013).

72. Kuleshov, M. V. et al. Enrichr: a comprehensive gene set enrichment analysis web server 2016 update. Nucleic Acids Res. 44, W90-W97 (2016).

73. Colaprico, A. et al. TCGAbiolinks: an R/Bioconductor package for integrative analysis of TCGA data. Nucleic Acids Res. 44, e71 (2016).

\section{Acknowledgements}

We thank CERCA Program/Generalitat de Catalunya for their institutional support. This work was also supported by the Fundació La Marató de TV3, grant number \#20131610 (S.G.), the AECC-Junta de Barcelona (S.G.), the Fundación Científica de la AECC under grant GCB13131578DEÁ (O.M.T.), the Ministerio de Economía y Competitividad (MINECO) and the Instituto de Salud Carlos III (ISCIII), co-financed by the European Development Regional Fund, 'A way to achieve Europe' ERDF, under grant numbers SAF2014-56894-R (S.G.), SAF2014-55000-R (M.E.), CB16/12/00312 (M.E.) and PI16/ 01898 (A.V.), the Health and Science Departments of the Catalan Government (Generalitat de Catalunya), and the European Union's Horizon 2020 research and innovation program under the Marie Sklodowska-Curie, grant agreement number 799850 (A.V., L. F.). C.O.-M. is a pre-doctoral fellow funded by the Basque Government (PRE_2013_1_1009). A.O.-G. is a pre-doctoral fellow funded by MINECO (BES-2015071452). M.E. is an ICREA Research Professor.

\section{Author contributions}

Conception and design: S.G., C.O.-M. and L.F. Development of methodology: C.O.-M., A.S.-C., A.O.-G., R.B.-S., M.S., T.R., J.P., A.G., M.M.-I., D.H.-M., L.F. and S.G. Acquisition of data (provided animals, acquired and managed patients, provided facilities, etc): O.M.T., A.V., and M.E. Analysis and interpretation of data (e.g., statistical analysis, biostatistics, computational analysis): D.P., M.E.C.-C., M.C.deM., A.M.-C. and A.G. Writing, review and/or revision of the paper: All authors. Administrative, technical or material support (i.e., reporting or organizing data, constructing databases): D.P., M.E. C.-C. and M.C.deM. Study supervision: S.G.

\section{Additional information}

Supplementary Information accompanies this paper at https://doi.org/10.1038/s41467019-11910-6.

Competing interests: A. Villanueva is founder and shareholder of Xenopat S.L. (Barcelona, Spain). The other authors declare no competing interests.

Reprints and permission information is available online at http://npg.nature.com/ reprintsandpermissions/

Peer review information: Nature Communications thanks Yingqun Huang and Ivan Stamenkovic for their contribution to the peer review of this work. Peer reviewer reports are available.

Publisher's note: Springer Nature remains neutral with regard to jurisdictional claims in published maps and institutional affiliations.

pen Access This article is licensed under a Creative Commons Attribution 4.0 International License, which permits use, sharing, adaptation, distribution and reproduction in any medium or format, as long as you give appropriate credit to the original author(s) and the source, provide a link to the Creative Commons license, and indicate if changes were made. The images or other third party material in this article are included in the article's Creative Commons license, unless indicated otherwise in a credit line to the material. If material is not included in the article's Creative Commons license and your intended use is not permitted by statutory regulation or exceeds the permitted use, you will need to obtain permission directly from the copyright holder. To view a copy of this license, visit http://creativecommons.org/ licenses/by/4.0/.

(C) The Author(s) 2019 